\title{
Triggering of tremors and slow slip event in Guerrero, Mexico, by the 2010 Mw 8.8 Maule, Chile, earthquake
}

\author{
Dimitri Zigone, ${ }^{1,2}$ Diane Rivet, ${ }^{1}$ Mathilde Radiguet, ${ }^{1}$ Michel Campillo, ${ }^{1}$ Christophe Voisin, ${ }^{1}$ \\ Nathalie Cotte, ${ }^{1}$ Andrea Walpersdorf, ${ }^{1}$ Nikolai M. Shapiro, ${ }^{3}$ Glenn Cougoulat, ${ }^{1}$ \\ Philippe Roux, ${ }^{1}$ Vladimir Kostoglodov, ${ }^{4}$ Allen Husker, ${ }^{4}$ and Juan S. Payero ${ }^{4}$ \\ Received 12 January 2012; revised 19 July 2012; accepted 22 July 2012; published 11 September 2012.
}

[1] We investigate the triggering of seismic tremor and slow slip event in Guerrero (Mexico) by the February 27, 2010 Maule earthquake (Mw 8.8). Triggered tremors start with the arrival of $S$ wave generated by the Maule earthquake, and keep occurring during the passing of ScS, SS, Love and Rayleigh waves. The Rayleigh wave dispersion curve footprints the high frequency energy envelope of the triggered tremor, indicating a strong modulation of the source of tremors by the passing surface wave. This correlation and modulation by the passing waves is progressively lost with time over a few hours. The tremor activity continues during the weeks/months after the earthquake. GPS time series suggest that the second sub-event of the 2009-2010 SSE in Guerrero is actually triggered by the Maule earthquake. The southward displacement of the GPS stations starts coincidently with the earthquake and tremors. The long duration of tremors indicate a continuing deformation process at depth, which we propose to be the second sub-event of the 2009-2010 SSE. We show a quasi-systematic correlation between surface displacement rate measured by GPS and tremor activity, suggesting that the NVT are controlled by the variations in the slip history of the SSE. This study shows that two types of tremors emerge: (1) Those directly triggered by the passing waves and (2) those triggered by the stress variations associated with slow slip. This indicates the prominent role of aseismic creep in the Mexican subduction zone response to a large teleseismic earthquake, possibly leading to large-scale stress redistribution.

Citation: Zigone, D., et al. (2012), Triggering of tremors and slow slip event in Guerrero, Mexico, by the $2010 \mathrm{Mw} 8.8 \mathrm{Maule}$, Chile, earthquake, J. Geophys. Res., 117, B09304, doi:10.1029/2012JB009160.

\section{Introduction}

[2] Since their discovery in California [Linde et al., 1996], Japan [Hirose et al., 1999] and Cascadia [Dragert et al., 2001], slow slip events (SSE) have been observed in a large variety of subduction zones (Japan, Cascadia, Mexico, Costa Rica, New Zealand, Alaska, see Schwartz and Rokosky [2007] for a review). These SSEs are sometimes associated with strong activities of seismic tremors in the so-called Episodic Tremor and Slip (ETS) observed for the first time in Cascadia by Rogers and Dragert [2003]. With the improving

\footnotetext{
${ }^{1}$ Institut des Sciences de la Terre, Université Joseph Fourier, CNRS, IRD, Grenoble, France.

${ }^{2}$ Now at Department of Earth Sciences, University of Southern California, Los Angeles, California, USA.

${ }^{3}$ Institut de Physique du Globe de Paris, Sorbonne Paris Cité, CNRS, UMR7154, Paris, France.

${ }^{4}$ Instituto de Geofísica, Universidad Nacional Autónoma de México, México City, Mexico.

Corresponding author: D. Zigone, Department of Earth Sciences, University of Southern California, Los Angeles, CA 90089-0740, USA. (dimitri.zigone@ujf-grenoble.fr)

(C)2012. American Geophysical Union. All Rights Reserved. 0148-0227/12/2012JB009160
}

of GPS measurements, correlations between tremor and SSEs have been established in Cascadia and southwest Japan and there may exist similar correlations in Alaska [Ohta et al., 2006; Peterson and Christensen, 2009], and Costa Rica [Brown et al., 2005; Outerbridge et al., 2010]. This study focuses on the Guerrero gap, located along the Mexican subduction zone (Figure 1) where some of the largest SSE were observed [Kostoglodov et al., 2003]. During the last decade, 4 SSE have been reported with a recurrence interval of about 4 years (1998, 2002, 2006 and 2009-2010) [Cotte et al., 2009; Walpersdorf et al., 2011]. They reach equivalent seismic moment up to $\mathrm{Mw}=7.6$ with a southward surface displacement up to 5-6 cm. The 2009-2010 SSE appears more complex than the previous SSE in the region [Kostoglodov et al., 2003; Radiguet et al., 2011; Vergnolle et al., 2010]. The slip takes place on two different portions of the fault. The total duration of the SSE is about 14 months, which is much longer than the previous events in Guerrero (about 6 months).

[3] These SSEs are accompanied by a strong but irregular tremor activity located in central and northern Guerrero [Payero et al., 2008] where the subduction interface remains horizontal at $40 \mathrm{~km}$ depth [Kim et al., 2010; Kostoglodov 


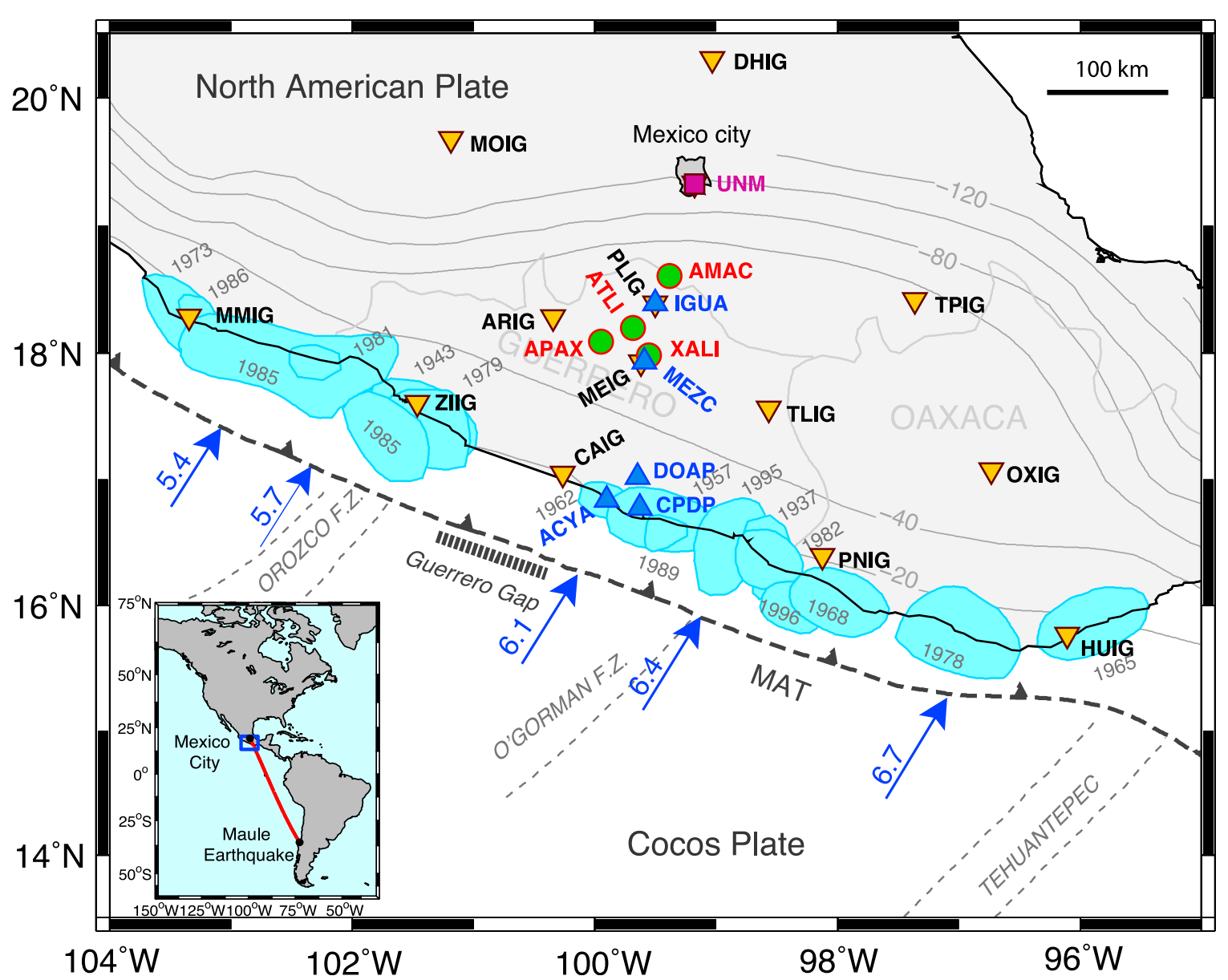

Figure 1. Seismotectonic map of Guerrero, Mexico [after Kostoglodov et al., 2003]. Inverse yellow triangles with black contours indicate the STS2 3 components stations from the Servicio Sismológico Nacional (SSN) of Mexico. The names of these stations are indicated in black. The green dots with red contours indicate the G-GAP miniarrays (1 CMG40 3 components sensor and 6 vertical short period sensors). The G-GAP array's names are indicated in red. The purple square is the STS1 broadband UNM Geoscope station in Mexico City. The blue triangles are the GPS stations used in this study (the names are in blue). The blue arrows indicate the direction and velocity in $\mathrm{cm} / \mathrm{yr}$ of the PVEL relative plate motion between the Cocos and North American Plate [DeMets et al., 2010]. Little blue patches represent the major earthquakes rupture zones. Thin gray lines show the isodepth contours of the subducted oceanic slab [after Pardo and Suarez, 1995]. The insert presents the great circle path between the epicenter of Maule earthquake and UNM station in Mexico City (red line). The blue square indicates the location of the main map.

et al., 1996; Pardo and Suarez, 1995; Perez-Campos et al., 2008]. Recent studies [Husker et al., 2012; Kostoglodov et al., 2010] reveal that the NVT activity in Guerrero is not simply correlated with the SSE. Even if the slow-slip is accompanied by a large amount of tremors, significant tremor activity is also observed between slip events, composing the background tremor activity and located further north from the SSE region.

[4] In this study we investigate the triggering of tremors and slip events in Mexico by the great 2010 Maule earthquake (Mw 8.8) that occurred on February 27, 2010 at 6:34:14 (UT) off the coast of Chile. Dynamic triggering of seismic tremors by distant earthquakes has been observed in several regions (e.g., Japan, California, Cascadia, Taiwan) in the past few years [Ghosh et al., 2009a; Miyazawa and Brodsky, 2008; Miyazawa and Mori, 2005, 2006; Peng and Chao, 2008; Peng et al., 2008, 2009; Rubinstein et al., 2009, 2007] during the passage of Love waves [Peng and Chao, 2008; Rubinstein et al., 2007] or Rayleigh waves [Miyazawa and Mori, 2005, 2006]; exceptionally, the passage of P waves [Ghosh et al., 2009a] or S waves [Shelly et al., 2011] might trigger tremors too. Triggered tremors by regional earthquakes have also been reported in California [Guilhem et al., 2010]. By contrast, there is only few evidence of triggered SSE by distant earthquakes. Rubinstein et al. [2009] suggested that large ETS events, which persist for more than one week, are sometimes dynamically triggered in the Cascadia subduction zone. Recently Itaba and 
Ando [2011] observed a small slow slip event (equivalent magnitude 5.3) associated to the Mw 7.6 Tonga earthquake of March 2009.

\section{Data}

[5] The 2010 Maule earthquake (Mw 8.8) was recorded by the broadband sensors of the Servicio Sismológico Nacional de Mexico (SSN) and the very broadband UNM (GEOSCOPE) station in Mexico City. In addition, several seismic miniarrays (referred hereafter as G-GAP network) have been deployed in central Guerrero since 2009 to study the tremor activity previously observed in that region [Husker et al., 2012; Kostoglodov et al., 2010; Payero et al., 2008]. Each miniarray is composed of one broadband sensor (CMG40-60s by Guralp) in the center surrounded by $61 \mathrm{~s}$ period sensors for a total aperture of about $150 \mathrm{~m}$ per array (Figure S1 in the auxiliary material). ${ }^{1}$ To study the SSE, we use 5 GPS stations located in Guerrero along a profile from Mexico City to Acapulco (Figure 1). Tremors are identified in the $2-8 \mathrm{~Hz}$ frequency band as bursts of non-impulsive seismic energy. These bursts are coherent among 12 stations used in this study (see Figure 2 for the seismograms and Figure S2 in auxiliary material for a map of all 30 stations). The station UNM is used as a reference because it is equipped with a STS1 seismometer and it is located far away from the tremor zone.

\section{Triggering and Modulation of Tremor Activity by the Mw 8.8 Chile Earthquake}

\subsection{Immediate Tremor Triggering}

[6] We first analyze a limited time window corresponding to the passing of seismic waves from the Maule earthquake. Figure 3 a shows a comparison of band-pass $(2-8 \mathrm{~Hz})$ filtered record at ATLI miniarray and the seismograms recorded by the broadband UNM station in Mexico City on the transverse (green trace) and vertical (blue trace) components. Knowing the difference of $91 \mathrm{~km}$ in epicentral distance between the two stations, the time shift of the traces between the two records is $21 \mathrm{~s}$, based on a $4.4 \mathrm{~km} / \mathrm{s}$ Love wave phase velocity. We observe individual triggered bursts of 60 to $90 \mathrm{~s}$ duration associated with $\mathrm{S}, \mathrm{ScS}$ and $\mathrm{SS}$ phases (arrival time $11 \mathrm{~min}, 12 \mathrm{~min} 20 \mathrm{~s}$ and $16 \mathrm{~min} 10 \mathrm{~s}$ respectively). The energy burst associated with the $\mathrm{P}$ wave arrival is not a tremor but the high-frequency energy associated to the teleseimic $P$ waves that is not yet attenuated. On Figure 4 we compare two band pass filterings: between 2 and $8 \mathrm{~Hz}$ (see Figure 4b) as in Figure 3 and between 5 and $15 \mathrm{~Hz}$ (see Figure $4 \mathrm{a}$ ) on the traces recorded at station ATLI. The result clearly shows that the high frequency filtering suppresses the high frequency $\mathrm{P}$ wave but keeps the high frequency tremors associated to the S, Love and Rayleigh waves which confirms the teleseimic origin of the high frequency energy associated to $P$ wave (see Figure 4). Figure 4 also exhibits a small local earthquake (see Figure 3 ) recorded in the same time window which has been located at the southeast boundary of the Guerrero state by the SSN network.

\footnotetext{
${ }^{1}$ Auxiliary materials are available in the HTML. doi:10.1029/ 2012JB009160.
}

[7] Higher energy tremor bursts are associated with the large-amplitude surface waves. The Love waves trigger a $80 \mathrm{~s}$ duration tremor burst. The Rayleigh waves trigger a more complex tremor, made of successive bursts embedded in a continuous sustained activity, for a total duration of about $10 \mathrm{~min}$. A careful look at the envelope of these bursts (Figure 3a, purple trace) shows a temporal decrease of their energies and durations. The variation of duration of the burst with time suggests a possible relation with the dispersion of the incoming long period signal. The envelope of the high frequency tremor is high-pass filtered at $10 \mathrm{~s}$ in order to emphasize the burst activity within the tremor (Figure 3a, red trace). The S-transform spectrogram [Stockwell et al., 1996] of this trace is then computed and compared with the S-transform spectrograms obtained from the raw data recorded at UNM station (white contours) on the transverse (Figure 3c) and vertical (Figure 3d) components after taking into account the distance between the two sensors. The envelope of the burst triggered by the Love wave has an impulsive character and a duration of $50 \mathrm{~s}$ while the successive bursts triggered by the Rayleigh waves present modulations with an increasing frequency of their envelope with time. This particular frequency pattern has to be compared with the dispersion of the surface waves emitted by the Maule earthquake. As expected for a mostly oceanic path, the Love wave recorded at UNM station is characterized by a non-dispersive signal (the Gutenberg phase) similar to the envelope of the corresponding tremor burst. On the contrary, the time frequency pattern observed in the envelope of tremors (color plot) associated with the Rayleigh waves (Figure 3d) mimics the strong dispersion of these waves. This shows a clear modulation of the tremor activity by the dispersed Rayleigh waves. The presence of both Love and Rayleigh dispersion features in tremor envelopes indicates a strong modulation of the tremors sources by the passing surface waves that enhance and inhibit tremor bursts accordingly to the stress changes carried out by the teleseismic waves.

\subsection{Tremor Activity During the First 12h After the Maule Earthquake}

[8] In the previous subsection, we showed that the direct surface waves emitted by the Maule earthquake trigger and control the tremor activity of the Guerrero gap. It has been shown that the multiple surface waves of the Chile earthquake triggered microearthquakes [Jay et al., 2012; Peng et al., 2011]. Here we investigate the possibility of a triggering of tremor activity by the multiple surface waves (R2, R3, L2, L3) that are recorded at UNM during the $12 \mathrm{~h}$ following the Maule earthquake. Figure 5a presents the spectrogram analysis of the G-GAP miniarray ATLI data (Figure $5 \mathrm{~b}$ presents the corresponding envelopes) for the $12 \mathrm{~h}$ after the Maule earthquake and reveals several periods of tremor activity around $9 \mathrm{~h}, 10 \mathrm{~h}, 14 \mathrm{~h}$ and $16 \mathrm{~h}$ (UTC). They present higher energy tremors during a longer duration. The strong energy pattern visible at $7 \mathrm{~h} 50$ is not a tremor but the arrival of the T phase, which is an acoustic wave propagating in the "SOFAR channel" with a $5 \mathrm{~Hz}$ dominant frequency [Okal, 2008]. For comparison, Figures 5c and 5d show the signals recorded at transverse and vertical components of the UNM station (low-passed at $0.01 \mathrm{~Hz}$ ). 


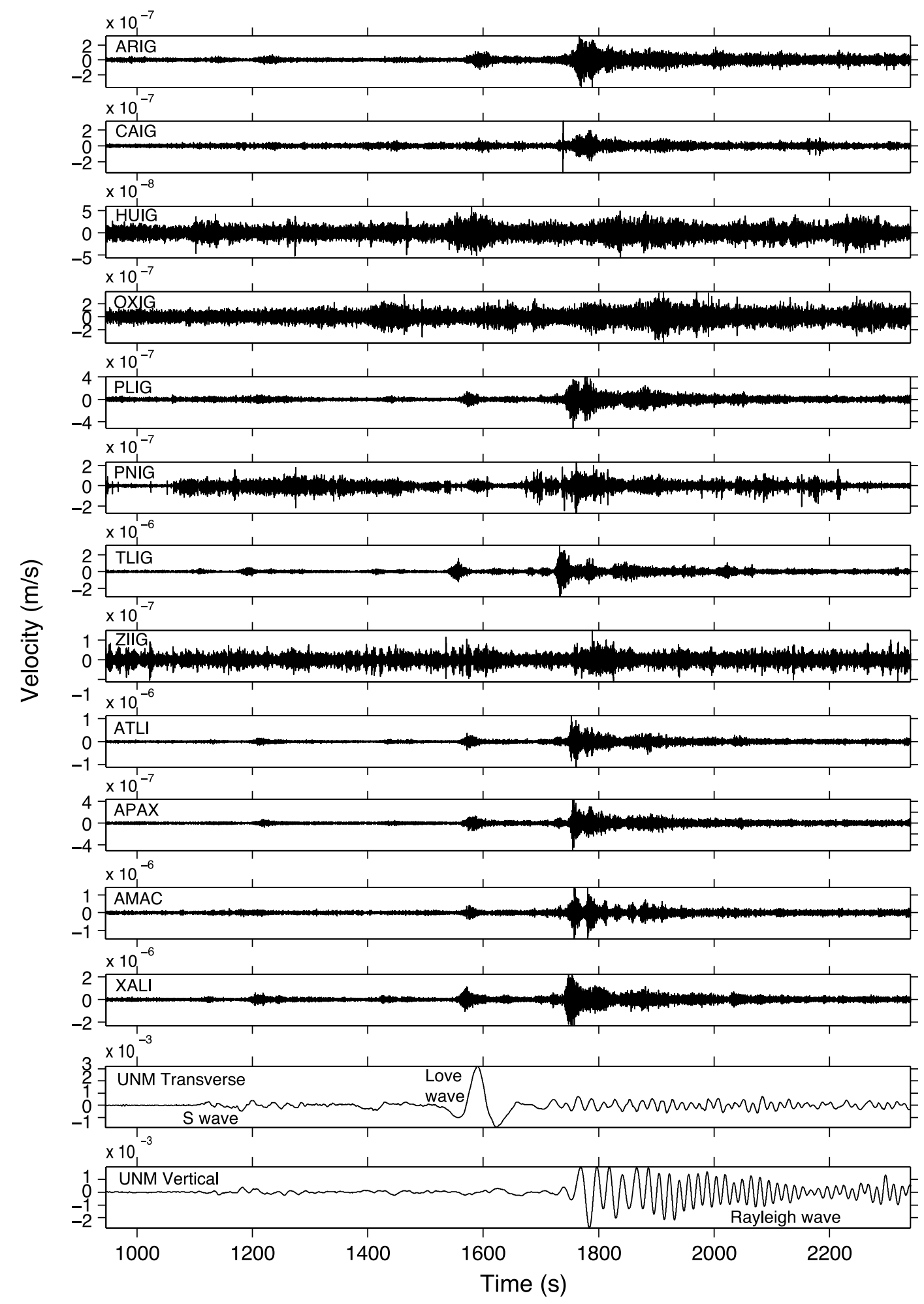

Figure 2. Section of 12 north-south seismograms obtained on the broadband sensors of the SSN and G-GAP networks. The traces are filtered between 2 and $8 \mathrm{~Hz}$ to exhibit the tremors. At the bottom are presented the raw transverse and vertical components of the UNM station in Mexico City.

[9] This temporal comparison reveals that first two periods of activity (9h UT and 10h UT) correspond to the arrivals of multiple surface waves that travel along the great circle. The tremor activity at $9 \mathrm{~h}$ is associated with the $\mathrm{R} 2$ waves (see Figure S3 in the auxiliary material for a detailed comparison). Similarly, the strong $10 \mathrm{~h}$ tremor activity is correlated to the L3 and R3 arrivals (see Figure S4 in the auxiliary material for a detailed comparison). At the same 

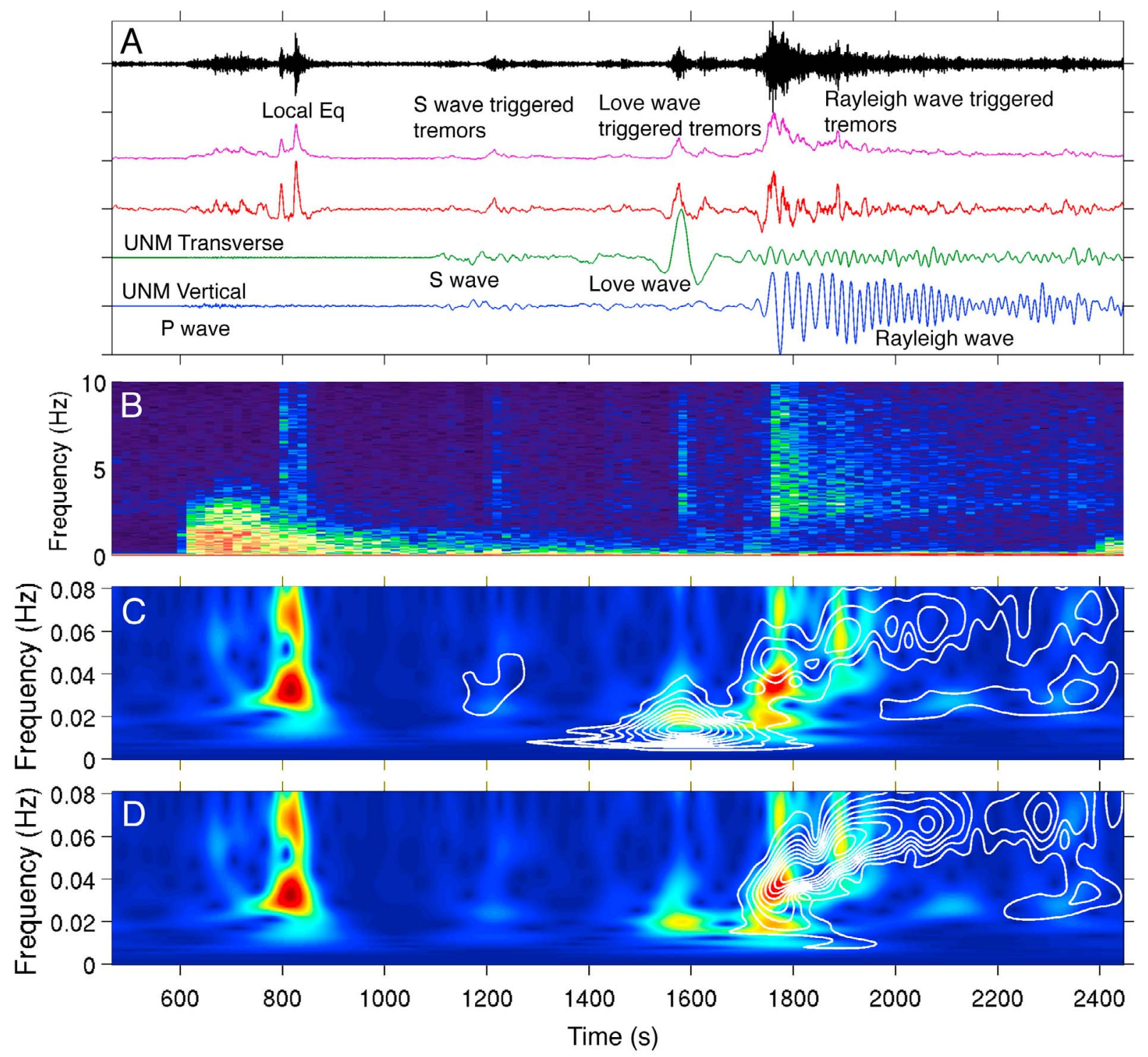

Figure 3. (a) Comparison between the $2-8 \mathrm{~Hz}$ filtered data recorded on a short period sensor at ATLI (black trace) and the broadband record of the Chilean earthquake at the UNM station in Mexico City for the transverse (green trace) and vertical (blue trace) components. The time scale is in seconds and starts at the initial time of the Maule earthquake. The envelope function of the ATLI data is in purple. The red trace is the high pass filtered envelope function that clearly shows the variations in the tremor activity. There is a clear triggering of tremor in ATLI by the S wave packet, the Love wave and the Rayleigh wave. A careful look at the envelope of this triggered tremor (Figure 3a, purple trace) shows a decrease of the seismic energy radiated by the NVT bursts and a temporal decrease of their duration. This observation reveals a dispersion in the envelope of the triggered tremor. (b) Spectrogram of the data recorded at ATLI. (c, d) We compare the S-transform spectrogram obtained for the high pass filtered envelope presented in Figure 3a (color plot) with the S-transform spectrograms obtained for the raw broadband records at UNM station (white contours). Figure 3c shows the transverse component, and Figure 3d shows the vertical component. The comparison of the dispersion observed in the envelope of tremors (color plot) with the one associated with Rayleigh waves recorded in Mexico City (Figure 3d) shows the modulation of the tremors by the dispersed waves.

time, very strong and long-duration tremor episodes at 14 and $16 \mathrm{~h}$, are not associated with particular multiple surface waves. This indicates that after triggering by the first direct surface waves $(\mathrm{R} 1, \mathrm{~L} 1)$ and a few multiples surface waves (R2, L3, R3), the tremor activity continues as a process independent of the triggering waves.

\subsection{Locating Sources of Non-volcanic Tremors}

[10] Seismic tremors are difficult to locate because of the lack of clear impulsive wave arrivals. Several different techniques are used to overcome this difficulty [Ghosh et al., 2009b; Husker et al., 2010; Kostoglodov et al., 2010; Obara, 2002; Ryberg et al., 2010; Shelly and Hardebeck, 


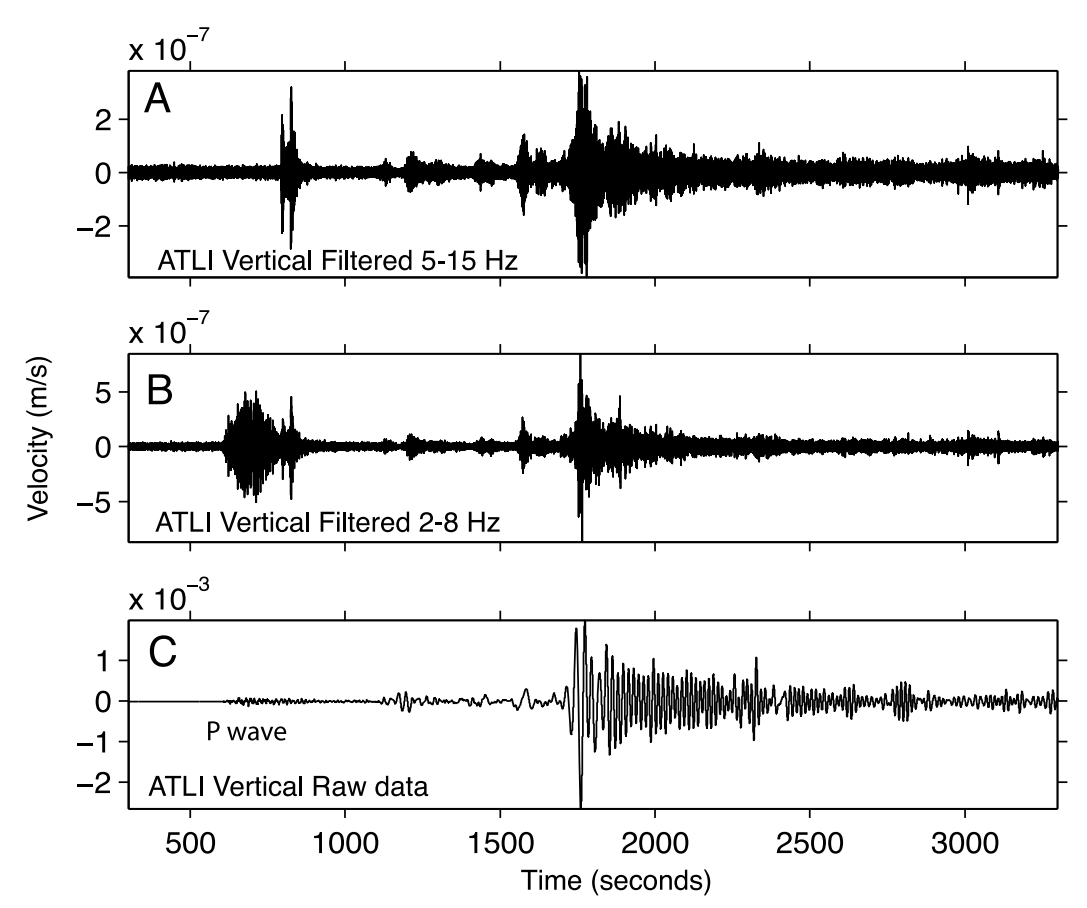

Figure 4. (a) Data recorded on the vertical component at ATLI station and filtered between 5 and $15 \mathrm{~Hz}$. (b) Same as Figure 4a but filtered between 2 and $8 \mathrm{~Hz}$. (c) Raw data recorded at ATLI.

2010]. With these techniques, it was possible to prove tremor migration, along strike of the subduction zones [Obara, 2002; Obara and Sekine, 2009; Shelly et al., 2007], but also downdip or updip in the Cascadia subduction zone [Ghosh et al., 2009b, 2010; Ide, 2010]. In this study, we have an opportunity to investigate the possibility of tremor migration during their triggering by teleseismic waves. We analyze the epicenters of the two types of tremors (the direct instantaneous triggering by the incoming waves and ambient activity several hours after the passage of surface waves). Note that the subduction interface is almost horizontal in the central part of the region of study. The locations are obtained by two different methods.

[11] The first one is a slightly modified version of the envelope cross correlation method (ECC) [Obara, 2002]. It uses the data recorded on both SSN and G-GAP networks. After the initial computation of the envelope functions, we high pass filter these envelopes to extract the burst variations (see Figure 3a, red trace). We then compute the correlations of these high pass filtered envelops. As the low frequency content of the envelopes has been removed, the cross correlation functions present the time delay with a single and short duration peak, which allows a better picking of the maximum of the correlation. We then locate the tremors using the relative time delays and a $1 \mathrm{D} S$ wave velocity model proposed by Campillo et al. [1996].

[12] The second method uses the array data and a linear beam-forming approach similar to Ghosh et al. [2009b], Ryberg et al. [2010], and Ueno et al. [2010]. The processing technique assumes local plane waves over the array and applies a delay-and-sum approach for a range of horizontal slownesses. This method provides the directions of the coherent waveform from the tremor signal selected on a given time window (here 30 s with $50 \%$ overlap). The beamforming algorithm is usually performed in the frequency domain. We first compute the cross-spectral density matrix $\mathrm{K}$ of the data:

$$
K_{i j}(\omega)=d_{i}(\omega) \cdot d_{j}^{*}(\omega)
$$

where $d_{i}(\omega)$ is the data recorded at sensor $c_{i}$ and $d_{i}^{*}$ is the transpose and conjugate of $\mathrm{d}_{\mathrm{i}}$. Then we create synthetics data $e_{i}(\theta, v, \omega)$ (called the replica) for a synthetic source located at a given azimuth $\theta$ from the array for an assumed velocity model $v$ :

$$
e_{i}(\theta, v, \omega)=\exp \left(i 2 \pi \omega \frac{\left(X_{i} \sin (\theta)+Y_{i} \cos (\theta)\right)}{v}\right)
$$

where $\theta$ is the azimuth between the synthetic source and the array and $\left(\mathrm{X}_{\mathrm{i}}, \mathrm{Y}_{\mathrm{i}}\right)$ is the position of the sensor $\mathrm{c}_{\mathrm{i}}$. Finally, we calculate the correlation between the data and the replica. If the data and the replica are perfectly coherent, the semblance value $\mathrm{P}$ is 1 . The results for each frequency are summed to obtain the semblance between the data and the replica for a specific frequency range:

$$
P(\theta, v)=\sum_{\omega}\left|e^{*} \cdot K \cdot e\right|
$$

[13] By testing all the possible azimuth and apparent velocities, the ambiguity function $P(\theta, v)$ indicates the probability of presence of the dominant noise source in terms of azimuth $\theta$ and apparent velocity. In order to increase the contrast of the ambiguity surface, the beam forming may also be performed coherently from the correlation functions of the seismic noise data [Cros et al., 2011]. 


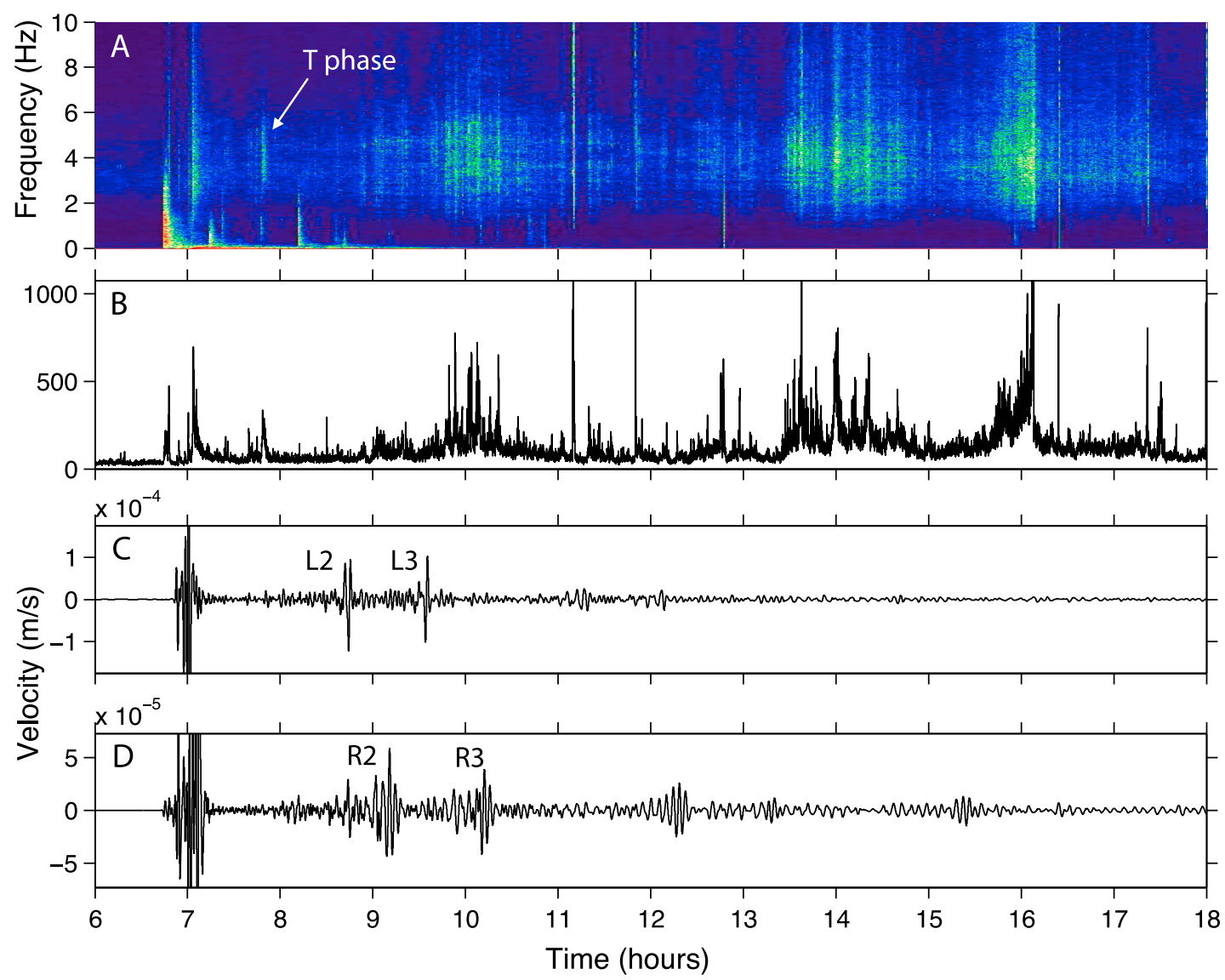

Figure 5. (a) Spectrogram of the data recorded on a short-period sensor in ATLI between 0 and $10 \mathrm{~Hz}$. The high energy in the $2-7 \mathrm{~Hz}$ frequency band corresponds to tremor activity. (b) Envelope of filtered data recorded in ATLI. (c) Transverse component of the UNM Geoscope station filtered between 100 and $1000 \mathrm{~s}$. The multiple of Love waves L2 and L3 can be identified and correspond to tremor activity. (d) Vertical component of the UNM Geoscope station filtered between 100 and $1000 \mathrm{~s}$. The multiples Rayleigh waves R2 and R3 are correlated to strong tremor activity. Note that the time is indicated in UTC and is different from what is presented on Figure 2 and 3.

The ambiguity surfaces for all miniarrays are then combined with a geometrical average to build the probability of presence of the source $\operatorname{PT}\left(\mathrm{x}_{\mathrm{j}}, \mathrm{y}_{\mathrm{j}}\right)$ at each position $\left(\mathrm{x}_{\mathrm{j}}, \mathrm{y}_{\mathrm{j}}\right)$ :

$$
P T\left(x_{j}, y_{j}\right)=\sqrt[N]{\prod_{i=1}^{N} P_{i}\left(\theta_{i}, V\right)}
$$

with $\mathrm{N}$ the number of arrays, $\theta_{\mathrm{i}}$ the azimuth between the point $\left(\mathrm{x}_{\mathrm{j}}, \mathrm{y}_{\mathrm{j}}\right)$ and the array $\mathrm{c}_{\mathrm{i}}$ and $\mathrm{V}$ a range of apparent velocities (here we choose all the velocities above the $\mathrm{S}$-wave velocity). Finally, we apply a threshold on each probability map (0.6) to detect and locate the tremors. An example of the method is presented in Figure S5 in the auxiliary material. The location errors are of a few kilometers when the source is inside the cluster of arrays. When the sources are located outside the cluster at moderate distances (between 0 and $50 \mathrm{~km}$ ), the locations errors are about $10 \mathrm{~km}$. For sources at about $100 \mathrm{~km}$ from the network, the resolution decreases with a mean error of about $25 \mathrm{~km}$.

[14] Figure 6a presents the location map of the tremor for a 10 min time window after the $\mathrm{S}$ waves arrivals obtained with the two methods (ECC for the Love and the first Rayleigh wave associated burst of tremor (inverse triangle) and beam forming for successive 30s time windows (color dots)). Despite a slight difference in latitude (beamforming locations appears closer to the coast than the ECC locations), both methods indicate that the tremors triggered by the first surface waves occur near the border between Guerrero and Oaxaca states, close to the TLIG station (blue dots and black inverse triangle in Figure 6a). This station shows the highest recorded amplitude of the tremors, which is consistent with a closer location to the source (see Figure S6 in the auxiliary material). This instantaneous triggered tremor activity occurs in a region where no tremors have been reported previously. This zone corresponds to the patch that slips during the second subevent of the 2009/2010 SSE in Guerrero (see part 4 or Walpersdorf et al. [2011] for a detailed description of the SSE). The sources then migrate in the northwest direction in the previously observed tremor zone [Husker et al., 2012; Kostoglodov et al., 2010; Payero et al., 2008]. This migration is characterized by a fast propagation velocity (about $125 \mathrm{~km}$ in $5 \mathrm{~min}$ which is about $400 \mathrm{~m} / \mathrm{s}$ ). Figure $6 \mathrm{~b}$ presents, by comparison, the location of tremors within the first day without the first 20 min presented on Figure 6a. The location is stable for tremors associated with 

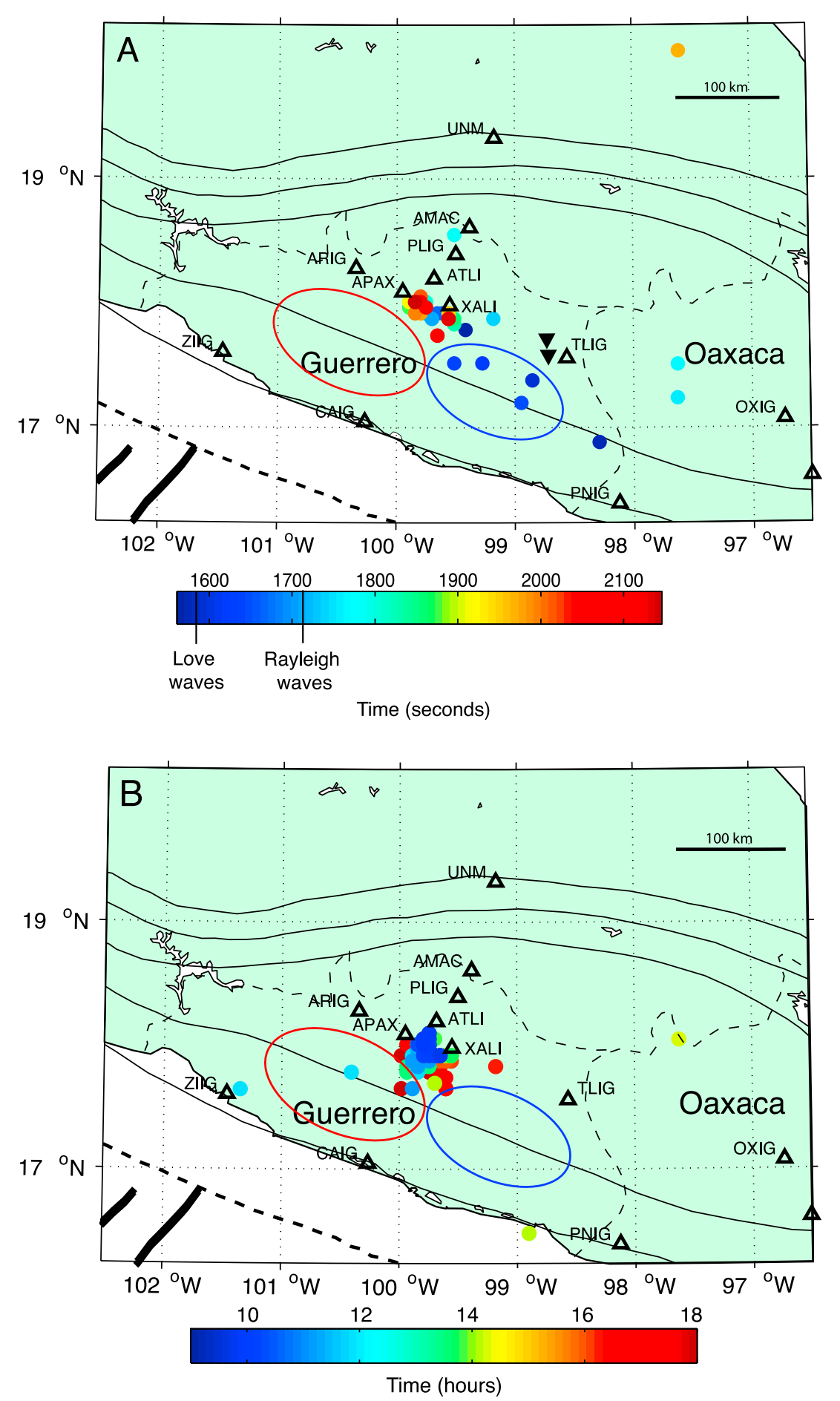

Figure 6. (a) NVT location map for the short-term triggering associated with the surface waves. Inversed black triangles indicate the locations obtained with the ECC method for the tremors triggered by Love and Rayleigh waves. The dots indicate the epicenters obtained with the beam-forming method. The color scale gives the time in seconds after the initial time of the Maule earthquake (see Figure 3 for the corresponding time series with the same time scale). As we focus only on surface waves, the color scale starts around $1600 \mathrm{~s}$, just before the Love wave arrival. (b) NVT location map for the long-term triggering. Black triangles indicate the stations and color dots are tremor locations. The color scale is in hours (see Figure 5 for the corresponding envelope and spectrogram). The surface projections of the two slip patches in 2009/ 2010 are shown schematically by the red (2009.5) and blue (2010.15) ellipses in the bottom of the maps [Walpersdorf et al., 2011]. 


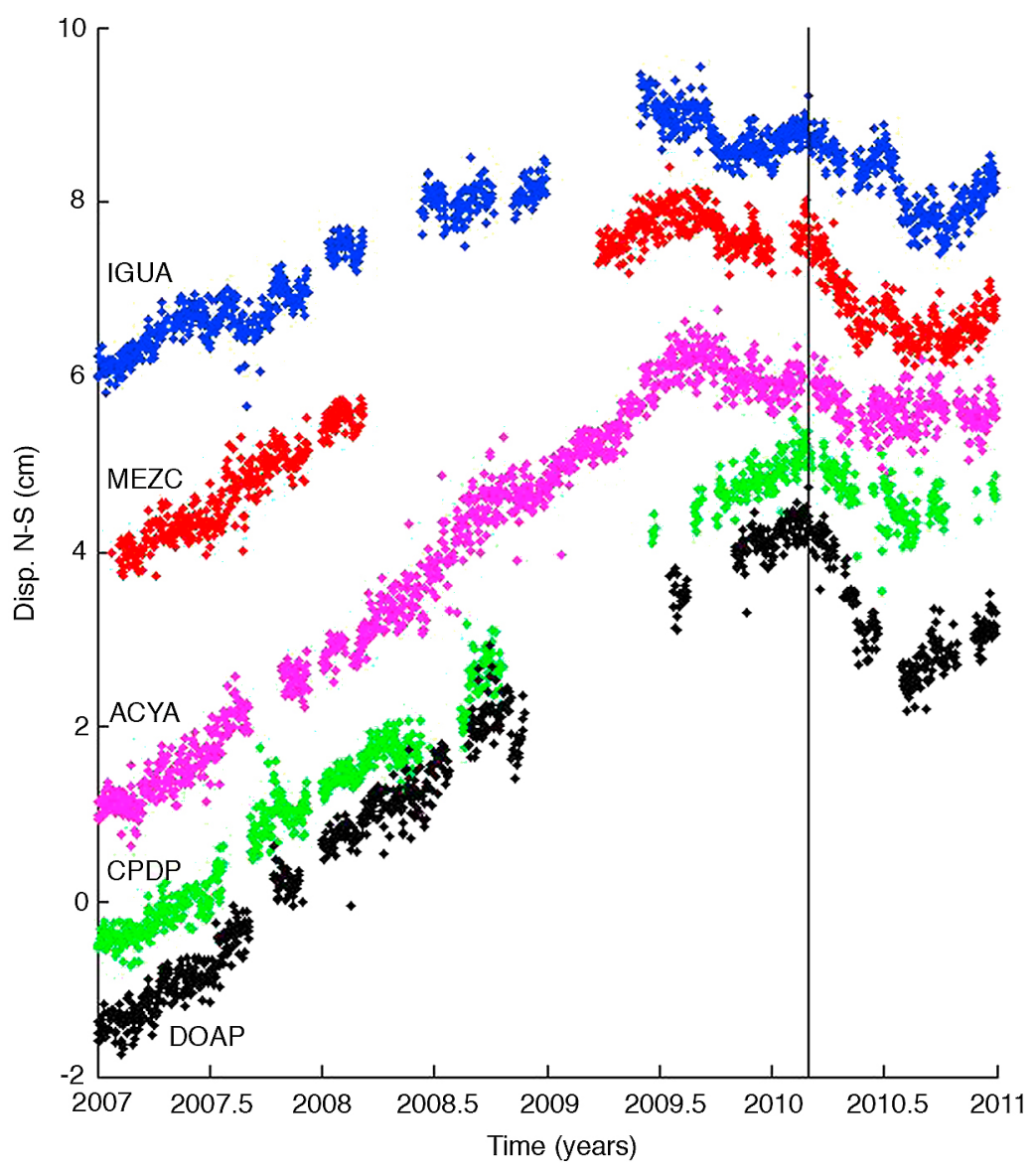

Figure 7. GPS North-south component time series between 2007 and 2011 for various stations in central and eastern Guerrero: IGUA (blue), MEZC (red), ACYA (purple), CPDP (green) and DOAP (black). Black line stands for the Chile earthquake occurrence.

multiple surface waves (9h UT and 10h UT) and uncorrelated tremors (14h UT and 16h UT). The sources are located in central Guerrero, which corresponds to the previously observed tremor zone [Husker et al., 2012; Kostoglodov et al., 2010; Payero et al., 2008].

\section{Triggering of a Slow Slip Event by the Mw 8.8 Chile Earthquake}

[15] As seen in section 3.2, the correlation and modulation of tremor activity observed for the direct surface waves is progressively lost with time. At the first glance, it seems to exist a preserved correlation between R2, L3, R3 and fresh upsurges of tremor activity, but modulation is not visible anymore. After the passage of R3, even this apparent correlation is lost and the strong tremor activity observed at 14h UT and 16h UT on the same day is not associated with multiple surface waves (Figure 5).

[16] We hypothesize that this qualitative change in the tremor activity may be related to some triggered deformation process at work, like slow slip, in the central Guerrero region. Indeed, Walpersdorf et al. [2011] describes the occurrence of a complex SSE in 2009-2010 in the form of a double event. We re-analyze the displacements observed at the surface using various GPS stations located in Guerrero and Oaxaca states. Figure 7 presents the GPS time series for
5 GPS stations located in central and eastern Guerrero for a sample rate of 1 position per day. The time series are calculated between 2007 (after the 2006 SSE in Guerrero [Radiguet et al., 2011; Vergnolle et al., 2010]) and the beginning of May, 2011 assuming a fixed North America plate. On IGUA, MEZC, and ACYA stations we can clearly see the onset of an SSE in July 2009 developing until the end of 2009 when the interseismic loading is recovered. The time of the Maule earthquake (vertical black line on Figure 7) marks the start of the second slip episode. By contrast the two other stations (CPDP and DOAP) present only the second part of slip-event that starts at the time of the Maule earthquake. These results shed a new light on the description on the 2009-2010 SSE in Mexico by Walpersdorf et al. [2011]. When the Maule earthquake occurs, the 2009 first sub-event already occurred, that increased the shear stress in the southern part of the Guerrero segment. This zone is then shaken by the seismic waves and evolves toward slip instability. Our results suggest that the Maule earthquake has triggered the second large event of the 2009-2010 SSE. Despite a very precise analysis [Vergnolle et al., 2010; Walpersdorf et al., 2011], the noisy residuals of the GPS time series make it difficult to determine with precision (day and hour) the onset of the slow slip. We conducted a kinematic analysis (with a sampling rate of $10 \mathrm{~s})$, as well as a static analysis using shorter sessions (6h, 


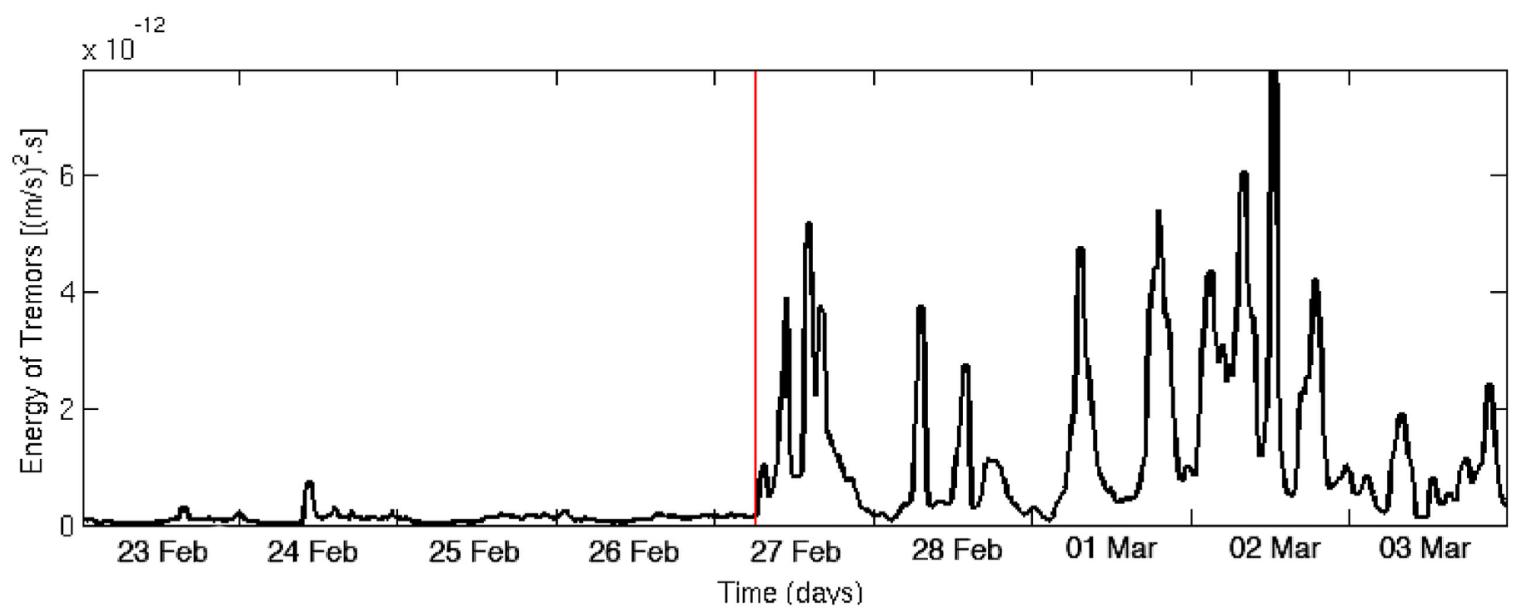

Figure 8. Energy of the seismic record between 2 and $8 \mathrm{~Hz}$ at the ATLI BHZ channel during 9 days between February 23, 2010 and March 3, 2010. Vertical red line presents the time of the earthquake. We clearly see the increase of the tremor activity after the earthquake. This sustained activity remains during 4 days after the earthquake with a peak on March 2, 2010, 3 days after the earthquake.

$8 \mathrm{~h}$ and $12 \mathrm{~h}$ ). Unfortunately, the results obtained do not allow determining the onset of the slip more precisely than the results for $24 \mathrm{~h}$ session (and sampling rate of $30 \mathrm{~s}$ ) presented here. A better time resolution can be achieved with seismological records, if, accordingly with our hypothesis, we use the tremor activities as a proxy to the evolution of slow slip at depth. Figure 8 presents the energy of the seismic records at the array ATLI from February 23 to March 3, filtered between 2 and $8 \mathrm{~Hz}$. This particular frequency band is the one where the activity of tremors is the most marked. We compute the average energy on 1-min time windows. The influence of local earthquakes that may contribute in this frequency band is discarded by applying a median filter to the computed energies (with medians calculated on 30 min time windows). Doing so, we keep only the signals with long durations associated with tremors [Husker et al., 2010]. Before the Maule earthquake (Figure 8, red vertical line), almost no tremor activity can be recorded. On the February 27,2010, starting at the time of the $\mathrm{P}$ waves arrival, the tremor activity shows a 50-fold increase. The four first peaks in the tremor activity are described in Figure 5a. Interestingly, the days following the earthquake present a sustained activity of tremors, with 2 to 5 peaks of activity per day. The maximum of activity is reached on March 2, 2010, three days after the Maule earthquake with a day-long strong tremor activity. Such a sustained activity suggests a continuing deformation at depth, most likely related to the second sub-event of the SSE.

\section{SSE and Tremors}

[17] In this section we discuss the possible link between the slow slip history observed with GPS and the associated tremor activity. Figure 9a presents the energy of the tremors recorded at the G-GAP arrays from March 2009 to January 2011, filtered between 2 and $8 \mathrm{~Hz}$. As we are only interested in the long term variations of the tremor activity, we average the energy on a $24 \mathrm{~h}$ time window. This explains why the variations of the energy during a day visible in Figure 8 are no more visible in Figure 9a. We clearly see the NVT burst triggered by the Chile earthquake at 2010.16 (labeled 0 ). This tremor episode has a total duration of about 10 days. Interestingly, we observed five other NVT episodes during the 2010 triggered SSE (labeled as 1, 2, 3, 4, and 5), and four other NVT episodes (labeled $-1,-2,-3$, and -4 ) between June and December 2009, during the first sub-event of the 2009-2010 SSE. Their durations range between 2 to 50 days with a mean recurrent time of about 50 days. The time distribution of seismic tremors during the 2010 SSE is similar to the one associated with the 2006 SSE where four large distinct NVT episodes were recorded [Kostoglodov et al., 2010].

[18] In Figure 9b we compare the GPS time series (IGUA in blue and MEZC in red) with the tremor activity (gray shaded areas, extracted from Figure 9a with a threshold of $0 \mathrm{~dB}$ ). The 2 GPS stations exhibit some variations in the displacement rate during the 2009-2010 SSE. The tremor 0 triggered by the Maule Earthquake is associated to an acceleration of motion to the South, interpreted as a slip acceleration at depth. We question now the generalization of this behavior for all the tremor episodes. By visual inspection of Figure 9b, this seems to be the case for Tremor episodes $-3,1,3,4,5$. In order to confirm the link between slip rate evolution and tremor activity, we compute the derivative of smoothed GPS time series in order to obtain the evolution of movement velocity at the surface. Figures $9 \mathrm{c}$ and $9 \mathrm{~d}$ present the results for the GPS stations IGUA and MEZC, which are the closest to the seismic array ATLI where the tremors are observed. The velocity measured at the surface confirms the previous visual analysis. The tremor episodes correspond to negative peaks in the movement velocity measured in IGUA (Figure 9c) and MEZC (Figure 9d), which is a slip toward the South. On the opposite, positive velocities (associated with a slip toward the North) correspond to periods of relative quiescence concerning the tremor activity, at the exception of the tremor episode of November 2009 (2009.85). These observations suggest that the tremors activity is controlled by the slow slip evolution. 
Similar results have recently been obtained in friction experiments where a correlation between the onset of slip acceleration and the emission of tremor-like signals has been observed [Zigone et al., 2011]. These authors show that tremor-like signals are emitted when the shear stress and/or the dilatation are at maximum. They propose that the temporary increase of stress induced by the rupture front propagation itself can trigger seismic tremors in zones where the stress state is close to its maximum. However, the spatial link between slow slip and tremors is not so clear in Mexico. Kostoglodov et al. [2010] show that the two phenomena are spatially separated in the 2006 SSE with a tremors zone
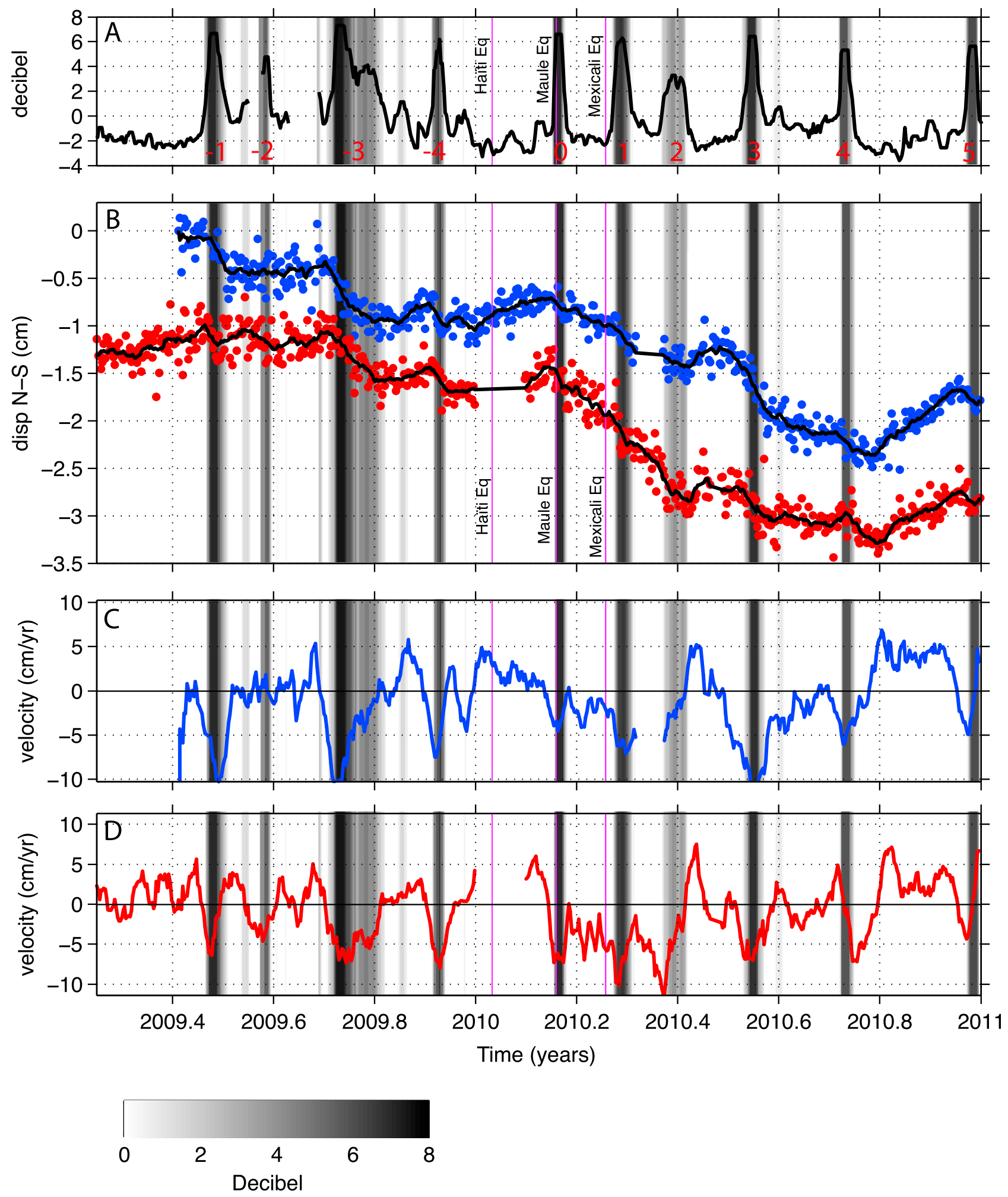

Figure 9 
located further north from the trench compared to the SSE zone. For the 2009/2010 SSE, Walpersdorf et al. [2011] also models a slip dislocation on two segments of the subduction interface located between 70 to $100 \mathrm{~km}$ from the trench (see red and blue ellipses on Figures $6 \mathrm{a}$ and $6 \mathrm{~b}$ ), further south compared to the main zone of tremors between Iguala and Mezcala [Husker et al., 2012; Kostoglodov et al., 2010; Payero et al., 2008].

\section{Discussion}

\subsection{Triggered Tremors and Modulation}

[19] The Mw 8.8 Maule earthquake in February 2010 triggered an intricate sequence of NVT activity in Guerrero, Mexico. The first NVTs appear as single short duration bursts of tremors associated with the oscillations of the incoming teleseismic shear body arrivals $(\mathrm{S}, \mathrm{ScS}, \mathrm{SS})$. The coincidence of the shear perturbations and the emergence of burst of tremors suggest that these phases generate conveniently oriented shear stresses variations that trigger burst of tremors of preferred oriented slip zones as proposed previously by Rubinstein et al. [2007]. However, due to the depth uncertainties, it is impossible to conclude on the locations of the tremor sources: it could be on the slab interface at $40 \mathrm{~km}$ depth or on conveniently oriented surfaces in the continental crust as suggested by the previously located tremors in Guerrero [Payero et al., 2008].

[20] After the body waves, a strong tremor activity is associated with the surface waves. These tremors present higher energies and longer duration, which indicates a higher level of perturbations, carried out by the incoming surface waves compared to the body waves. Clear modulation of tremor activity is evident in the strong bursts of tremor during the passage of large long-period Rayleigh waves. Modulations of tremors by surface waves has already been observed in several studies, associated with the dilatations produce by the Rayleigh waves [Miyazawa and Mori, $2005,2006]$ or by the shear stresses produced by Love waves [Rubinstein et al., 2007]. These authors show that the tremor turns on when there are positive dilatations for Rayleigh waves and updip shear perturbations for Love waves and turns off during compressions and downdip shear perturbations [Miyazawa and Brodsky, 2008; Miyazawa and Mori, 2006; Rubinstein et al., 2007]. Such a behavior gives intermittent tremor activities with burst of tremors when perturbations (dilatations or updip shear) are positive and no signal when perturbations are negative. This behavior differs from what we observe in Mexico during the passage of Rayleigh waves. In our case, the tremor activity is more continuous with a background activity of tremor. The intensity is enhanced during positive dilatations associated with the Rayleigh waves. This continuous aspect of the NVT is another evidence for a more global destabilization produced by the triggered SSE that is at work in Guerrero.

[21] Our results show that the instantaneous triggering associated with surface waves is a short-term process. The dispersion features of the surface waves directly control the duration of the tremor bursts as shown by the S-transform analysis as discussed is Section 3.1. Moreover, in Guerrero the NVTs triggered and modulated by the surface waves present a fast migration. By comparison the ambient "long term" activity of tremor during the first day (see tremor activity in Figure 5) reveals longer duration bursts of tremor with a persistent location in central Guerrero (see locations in Figure 6b). This observation is in agreement with a recent study in Japan [Obara, 2010] where tremors triggered and modulated by the tide present short duration and fast migrations compared to the ambient tremor with longer duration and stable locations. However, Obara et al. [2010] observed a depth discrepancy between short-term and longterm tremor locations along the plate interface. The shortterm tremors are located downdip of the area of the longterm tremor, along the subduction zone, which can be explained as the demarcation between the free-sliding and the transition zone. In our case, the NVT locations are at the same distance from the trench for both types of tremor. One possible explanation comes from the geometry of the subduction interface in central Guerrero, which remains horizontal from $80 \mathrm{~km}$ to $200 \mathrm{~km}$ from the coast and has a stronger dip in eastern Guerrero (Figure 1). The zone of tremor is less affected by frictional strength weakening with increasing depth due to the thermal condition like in other subduction zones. A transition from coupled to uncoupled interface is still present in Guerrero, but this transition could be more extended due to lower temperature gradient along the plate interface [Manea et al., 2004]. The consequences of such a geometry is that the possible variations in physical properties could be as strong along the strike as perpendicular to the trench, which may explain the migration from southeast to northwest of the "short-term" triggered tremors associated with surface waves.

[22] Our analysis reveals that two types of tremors are triggered in Guerrero by the Maule earthquake. The first type is associated to the body and surface waves and presents a strong modulation. These tremors are not located in the previously detected tremor zone [Husker et al., 2012; Kostoglodov et al., 2010; Payero et al., 2008]. Interestingly, this new zone of tremors corresponds to the patch that slips

\begin{abstract}
Figure 9. (a) Energy of the seismological record between 2 and $8 \mathrm{~Hz}$ at various BHZ channel (we combined the stations ATLI, APAX and ARIG to obtain the longest possible time series). Note that the scale is in decibels to facilitate the visualization of the evolution of tremors energy. The purple vertical lines represent the time of Haiti earthquake, Chile earthquake and Mexicali earthquake that occurred the 12th of January 2010, the 27th of February 2010 and the 4th of April 2010 respectively. The shaded areas in gray scale show the tremor activities with a threshold of 0 decibel. The numbers associated with each tremor episode are indicated in red. (b) Comparison between the GPS measurements and the tremor activity. The color dots are the GPS time series at 2 stations in Guerrero (IGUA in blue and MEZC in red located in the same zone as the seismological sensors). The black curves are the GPS time series smoothed with a moving average window of 10 days. The vertical purple lines indicate the time of the Haiti, Chile and Mexicali earthquakes. The shaded areas in gray scale are the tremors activities extracted from Figure 9a with the threshold of $0 \mathrm{~dB}$. (c, d) Derivative of the smoothed GPS time series recorded at IGUA (Figure 9c), MEZC (Figure 9d). These curves present the surface velocity, which is positive for displacement toward the north and negative in the south direction.
\end{abstract}



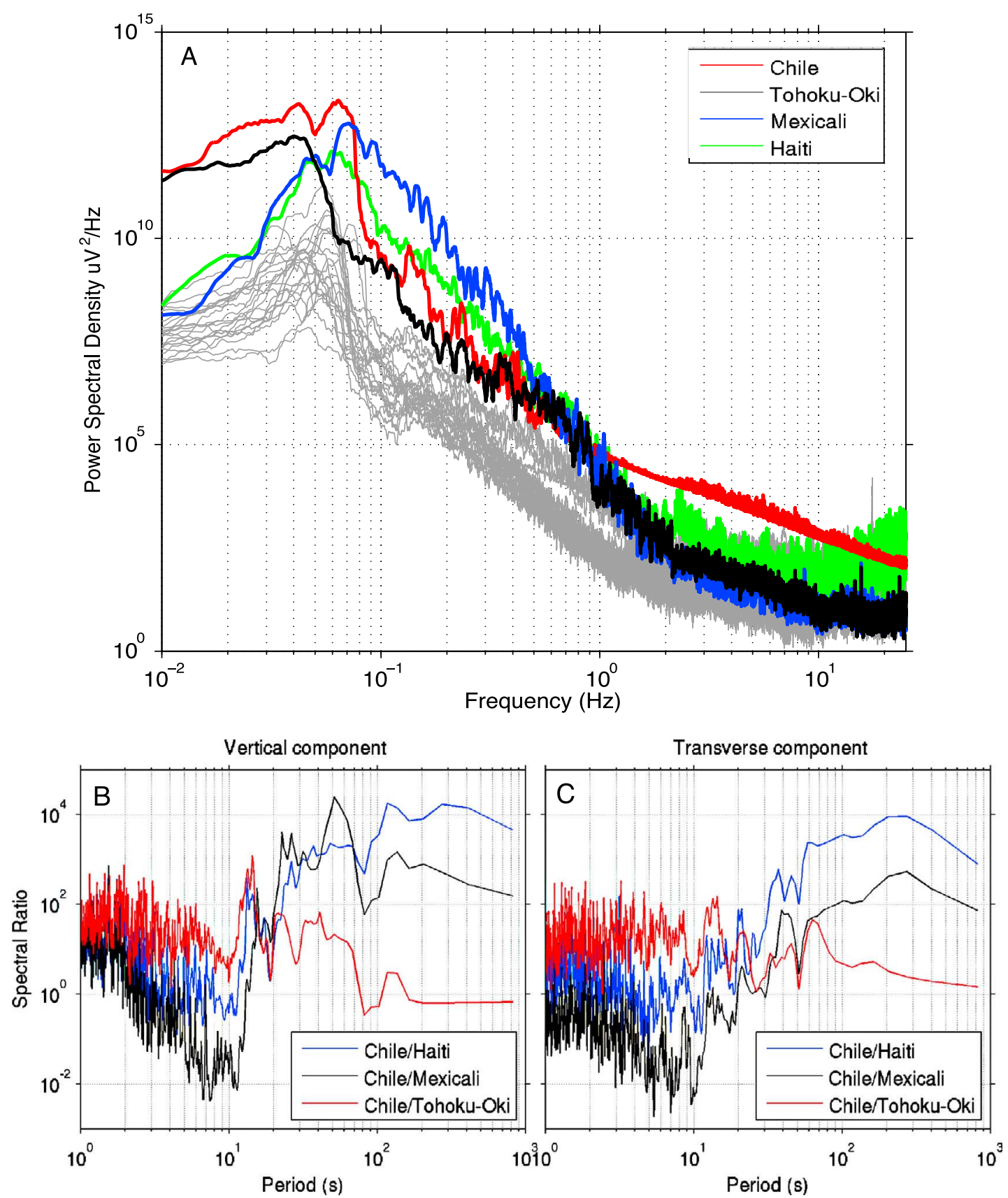

Figure 10. (a) Velocity Power spectral density computed from record of the 26 earthquakes recorded at ATLI. The color lines represent the spectra of the earthquakes that produced the largest PGV in ATLI (see Table 1): Chile (red), Tohoku-Oki (black), Mexicali (blue) and Haiti (green) earthquakes. (b, c) Spectral ratios between the Mw 8.8 Maule earthquake and 3 other earthquakes: Mw 7.0 Haiti earthquake (blue curve), Mw 9.0 Tohoku-Oki earthquake (black curve) and Mw 7.2 Baja California, Mexicali earthquakes (red curve). The four events have been recorded at the same UNM station in Mexico City (for Figures 10b and $10 \mathrm{c})$.

during the second subevent of the 2009/2010 SSE which is triggered by the Maule earthquake (Figure 6a). This spatial correspondence and the continuous aspects of the Rayleigh wave triggered tremors indicate a deformation of that part of the subduction zone due to the triggering of the SSE. The second type of tremors is located in the previously observed tremor zone in Guerrero [Husker et al., 2012; Kostoglodov et al., 2010; Payero et al., 2008] and is triggered by the variations in the slip evolution of the SSE. Figure 9 shows that the tremors are stronger at the peaks of movement velocity in the south direction. We may then suppose that, at the first order, tremor activity is concomitant with period of large strain rate, which is similar to the behavior observed for the seismic velocity changes in the crust during the 2006 SSE by Rivet et al. [2011]. 
Table 1. List of Earthquakes Recorded in ATLI Station ${ }^{a}$

\begin{tabular}{|c|c|c|c|c|c|c|c|c|c|c|}
\hline Year & Month & Day & Hour & Lat & Long & $\begin{array}{c}\text { Depth } \\
(\mathrm{km})\end{array}$ & Mw & $\begin{array}{l}\text { PGV } \\
(\mathrm{cm} / \mathrm{s})\end{array}$ & $\begin{array}{c}\sigma_{\mathrm{d}}(\mathrm{kPa}) \\
\text { Raw }\end{array}$ & $\begin{array}{c}\sigma_{\mathrm{d}}(\mathrm{kPa}) \\
\text { Filtered 30-100 s }\end{array}$ \\
\hline 2010 & 1 & 3 & $22: 36: 25.64$ & -8.78 & 157.35 & 10 & 7.1 & 0,0038 & 0,33 & 0,22 \\
\hline 2010 & 1 & 12 & 21:53:10.06 & 18.44 & -72.57 & 13 & 7.0 & 0,0419 & 3,59 & 0,31 \\
\hline 2010 & 2 & 26 & $20: 31: 26.97$ & 25.93 & 128.43 & 25 & 7.0 & 0,0010 & 0,08 & 0,04 \\
\hline 2010 & 2 & 27 & $06: 34: 11.53$ & -36.12 & -72.90 & 22 & 8.8 & 0,2623 & 22,48 & 11,37 \\
\hline 2010 & 3 & 11 & $14: 55: 27.51$ & -34.33 & -71.80 & 18 & 7.0 & 0,0064 & 0,55 & 0,09 \\
\hline 2010 & 4 & 4 & $22: 40: 43.10$ & 32.30 & -115.28 & 4 & 7.2 & 0,1458 & 12,50 & 0,72 \\
\hline 2010 & 4 & 6 & $22: 15: 01.58$ & 2.38 & 97.05 & 31 & 7.8 & 0,0105 & 0,90 & 0,20 \\
\hline 2010 & 5 & 9 & $05: 59: 41.62$ & 3.75 & 96.02 & 38 & 7.2 & 0,0033 & 0,28 & 0,08 \\
\hline 2010 & 5 & 27 & $17: 14: 46.57$ & -13.70 & 166.64 & 31 & 7.2 & 0,0048 & 0,41 & 0,10 \\
\hline 2010 & 6 & 12 & $19: 26: 50.46$ & 7.88 & 91.94 & 35 & 7.5 & 0,0038 & 0,33 & 0,20 \\
\hline 2010 & 6 & 16 & $03: 16: 27.55$ & -2.17 & 136.54 & 18 & 7.0 & 0,0013 & 0,11 & 0,02 \\
\hline 2010 & 7 & 18 & $13: 34: 59.36$ & -5.93 & 150.59 & 35 & 7.3 & 0,0025 & 0,22 & 0,04 \\
\hline 2010 & 7 & 23 & $22: 51: 12.45$ & 6.49 & 123.47 & 585 & 7.6 & 0,0061 & 0,52 & 0,08 \\
\hline 2010 & 8 & 4 & $22: 01: 43.62$ & -5.75 & 150.76 & 44 & 7.0 & 0,0011 & 0,09 & 0,02 \\
\hline 2010 & 8 & 10 & $05: 23: 44.98$ & -17.54 & 168.07 & 25 & 7.3 & 0,0023 & 0,20 & 0,07 \\
\hline 2010 & 8 & 12 & $11: 54: 15.58$ & -1.27 & -77.31 & 206 & 7.1 & 0,0028 & 0,24 & 0,05 \\
\hline 2010 & 9 & 3 & $16: 35: 47.77$ & -43.52 & 171.83 & 12 & 7.0 & 0,0038 & 0,33 & 0,08 \\
\hline 2010 & 9 & 29 & $17: 11: 25.94$ & -4.96 & 133.76 & 26 & 7.0 & 0,0010 & 0,08 & 0,06 \\
\hline 2010 & 10 & 25 & $14: 42: 22.46$ & -3.49 & 100.08 & 20 & 7.8 & 0,0022 & 0,19 & 0,06 \\
\hline 2010 & 12 & 21 & 17:19:40.66 & 26.90 & 143.70 & 14 & 7.4 & 0,0039 & 0,33 & 0,08 \\
\hline 2011 & 1 & 1 & 09:56:58.12 & -26.80 & -63.14 & 576 & 7.0 & 0,0027 & 0,24 & 0,01 \\
\hline 2011 & 1 & 2 & $20: 20: 17.78$ & -38.35 & -73.33 & 24 & 7.2 & 0,0051 & 0,43 & 0,14 \\
\hline 2011 & 1 & 13 & $16: 16: 41.54$ & -20.63 & 168.47 & 9 & 7.0 & 0,0046 & 0,40 & 0,19 \\
\hline 2011 & 1 & 18 & $20: 23: 23.48$ & 28.78 & 63.95 & 68 & 7.2 & 0,0030 & 0,26 & 0,12 \\
\hline 2011 & 3 & 9 & $02: 45: 20.33$ & 38.44 & 142.84 & 32 & 7.3 & 0,0038 & 0,33 & 0,21 \\
\hline 2011 & 3 & 11 & $05: 46: 24.12$ & 38.20 & 142.37 & 29 & 9.0 & 0,0664 & 5,69 & 4,26 \\
\hline
\end{tabular}

${ }^{\mathrm{a}}$ The dynamic stresses are calculated using the equation $\sigma_{\mathrm{d}}=\mathrm{G} \dot{\mathrm{u}} / \mathrm{v}_{\mathrm{s}}\left[\right.$ Jaeger and Cook, 1979], where G is the shear modulus, $\dot{\mathrm{u}}$ is the PGV and $\mathrm{v}_{\mathrm{s}}$ is the phase velocity. Here we choose a generic $30 \mathrm{GPa}$ shear modulus and a $3.5 \mathrm{~km} / \mathrm{s}$ Rayleigh wave velocity [Chao et al., 2012; Miyazawa and Brodsky, 2008]. The earthquakes listed in Table 2 are bold.

\subsection{Triggering of SSE and Tremors by Large Distant Earthquakes}

[23] Large distant earthquakes are known to trigger earthquakes either by static or dynamic triggering [ $\mathrm{Di}$ Carli et al., 2008; Freed, 2005; Gomberg et al., 2004; Gomberg and Johnson, 2005; Gomberg et al., 2001; Hill et al., 1993; King et al., 1994; Marsan and Lengline, 2008; Stein et al., 1994; Voisin et al., 2004]. More recently, it has been shown that large distant earthquakes can also trigger tremor activity downdip the subduction zones [Miyazawa and Mori, 2005, 2006; Rubinstein et al., 2009, 2007] and along continental faults [Ghosh et al., 2009a; Gomberg et al., 2008; Peng et al., 2008; Shelly et al., 2011]. It was proposed also that teleseismic events could trigger ETS [Rubinstein et al., 2009], and here we have shown that the Maule earthquake triggered a large slow slip event associated with an enhanced tremor activity.

[24] In the period 2009-2011, other large teleseismic earthquakes have been recorded in Mexico. Here we select the 26 earthquakes with a magnitude above 7 that have been recorded at the station ATLI between November 2009 (date of the installation) and March 2011. None of these earthquakes triggered tremors nor SSE in Guerrero. Figure 10a show the spectral content of these earthquakes on the vertical component. The color lines present the spectra for the events that produced the four largest Peak Ground Velocity (PGV) at ATLI (see Table 1 for a list of the earthquakes and the PGV). The red line is for the Maule earthquake. The three other events (Haiti, Mexicali and Tohoku-Oki) did not trigger any tremors or SSE (see Figures 9 and 10a). In the following we will focus on these 3 events compared to the Maule earthquake to discuss the possible constraints on the potential of a large earthquake to trigger tremors and/or SSE.

[25] Numerous studies have focused on the triggering of aftershocks and/or stable sliding on continental faults [Gomberg and Johnson, 2005; Gomberg et al., 2001; Voisin et al., 2004]. It emerges that the potential for triggering depends on the balance between the loading parameters (namely frequency and amplitude) and the intrinsic mechanics of the fault (friction law, state of stress).

Table 2. Characteristics of Highest PGV Earthquakes ${ }^{\mathrm{a}}$

\begin{tabular}{|c|c|c|c|c|}
\hline & Haiti Earthquake & Maule Earthquake & Mexicali Earthquake & Tohoku-Oki Earthquake \\
\hline Location & Haiti & Chile & Mexico & Japan \\
\hline Date & 12 Jan 2010 & 27 Feb 2010 & 04 Apr 2010 & 11 Mar 2011 \\
\hline Number of days with respect to Maule Eq & -46 & 0 & +36 & +377 \\
\hline Distance from Mexico city $(\mathrm{km})$ & 2801 & 6751 & 2165 & 10963 \\
\hline Latitude (deg) & 8.443 & -35.909 & 32.259 & 38.322 \\
\hline Longitude (deg) & -72.571 & -72.733 & -115.387 & 142.369 \\
\hline Depth $(\mathrm{km})$ & 13 & 35 & 10 & 32 \\
\hline Mw & 7.0 & 8.8 & 7.2 & 9.0 \\
\hline
\end{tabular}

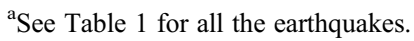


[26] Figures $10 \mathrm{~b}$ and $10 \mathrm{c}$ present the spectral ratios of the Maule earthquake over the 3 other earthquakes (details given in Table 2) for the vertical and transverse components measured at UNM. They reveal that the energy of the long periods surface waves are 2 to 4 orders of magnitude greater for the Maule earthquake between $10 \mathrm{~s}$ and $1000 \mathrm{~s}$ on the two components with respect to Haïti and Mexicali earthquakes. When compared to Tohoku-Oki rupture, these ratios drops in the range 1-100; Indeed the Maule and Tohoki-Oki ruptures have similar magnitudes, and the ratio tends to be 1 at longer periods. The discrepancy at higher frequencies is related to the shorter epicentral distance of Maule earthquake.

[27] From this spectral analysis, we can infer that the potential of an earthquake to trigger a SSE or tremors depends on its spectral content at long periods. This is particularly underscored by the Haiti and the Mexicali earthquakes that are depleted in energy above $10 \mathrm{~s}$. Indeed, even if the Mexicali earthquake produces high dynamic stresses in Guerrero (12.5 kPa see Table 1) the frequency content is too high to trigger tremors or SSE. To verify this observation we calculate the PGV and the corresponding dynamic stresses on 30-100 s band pass filtered traces for all earthquakes (see Table 1). Only two events emerge: the Maule (11.37 kPa) and Tohoku-Oki (4.26 kPa) earthquakes. This result is consistent with what is known for the potential of triggering of aftershocks and/or stable sliding: amplitudes at long periods are more likely to trigger activity [Gomberg and Johnson, 2005; Guilhem et al., 2010; Hill et al., 1993; Voisin, 2001, 2002].

[28] The case of Tohoku-Oki earthquake seems to contradict this result, as it has quite the same spectral content as the Maule earthquake and therefore could trigger also SSE and tremor activity. The absence of triggered activity can be related to the fact that after June 2010, most of the subduction interface prone to SSEs in Guerrero had already slipped. It is an unloaded interface that was subject to the passing of the high amplitude seismic waves. As expected from simple frictional models, the initial conditions at the plate interface seem to be a controlling factor for the triggering by long period waves. However, note that the precision of GPS measurements prevents the detection of SSEs with magnitude smaller than 6.5. Our argument is therefore based also on the absence of observable tremor burst.

[29] These three earthquakes help to constrain the conditions for SSE/tremor triggering: it is controlled by both the amplitude of the incoming waves and by the state of stress on the interface. Large perturbation with significant long period energy to trigger SSE suggests that a critical length exists like for dynamic triggering of earthquakes [Andrews, 1976; Dascalu et al., 2000; Uenishi and Rice, 2003; Voisin, 2001, 2002]. The fault has to be stressed in a region large enough for the instability to grow. Note that the energy of the Chile signal is larger than for the Haiti event for period larger than $10 \mathrm{~s}$, which is for wavelength longer that $40 \mathrm{~km}$ at least. This suggests that a large part of the subduction zone in Guerrero has to be solicited by large amplitudes long periods waves to trigger SSE.

\section{Conclusions}

[30] We observe that both SSE and tremors were triggered in Guerrero by the $2010 \mathrm{Mw} 8.8$ Maule earthquake. First, we detected tremors triggered in Guerrero by the passing S, Love and Rayleigh waves of the Maule earthquake. The greatest amount of tremor energy and duration accompanies the long-period Rayleigh waves, with smaller tremor bursts during the $\mathrm{S}$ and Love waves. For the Rayleigh wave triggered tremor, we observed the dispersion of Rayleigh waves in the envelopes of the tremor energy, which indicates a strong modulation of the tremor source by the passing surface waves. Second, the analysis of the GPS time series suggests that the second sub-event of the 2009-2010 slow slip event in Guerrero is actually triggered by the Maule earthquake. The displacement in the south direction started coincidently with the earthquake within the GPS resolution. Tremors started immediately with the arrival of the waves and lasted for a period much longer that the duration of the seismic waves, indicating a continuing process we identify as the SSE second sub-event.

[31] The link between NVTs and SSE is illustrated by the comparison between GPS time series and tremor activity during 2010. While it is known that tremors are not permanently active during the SSEs, neither located in the zone of largest slip [Husker et al., 2012; Kostoglodov et al., 2010], tremors bursts are observed when GPS time series exhibit a component of motion toward the South, indicating some slip at depth.

[32] We investigated the conditions of triggering by examining the behavior of the subduction during different large earthquakes. Not surprisingly, we found that the triggering of significant NVTs is controlled by both the amplitude of the incoming waves and by the state of stress on the interface. The observation of a large SSE triggered by a distant large earthquake is an important indication of a possible global mechanism of interaction between major active structures. A large SSE actually affects significantly the elastic stress on the subduction interface, including the seismogenic zone. In the months after the Maule earthquake, and its triggering effect, the state of stress increased in the coupled zone of the Guerrero subduction segment. Indeed this effect is delayed by the time necessary for the development of a transient creep event, that is several months and this stress increase has no direct impact so far, except possibly advancing the clock for the next earthquake.

[33] It was recently discussed in various meetings that very large earthquakes during the last century exhibit some form of temporal clustering. Indeed the statistical significance of the observation on such a short time window can be questioned [Michael, 2011]. In any case, the deterministic process responsible for such a clustering is unclear. A simple conceptual model of global clustering can be derived from the observation in Guerrero after the Maule earthquake. Our specific observation suggests that large slow slip events are triggered by mega earthquakes on the global scale, some of them being ignored with the resolution of our instrumentation, particularly in the past. They affect the stress level of the seismogenic parts of subduction interfaces, producing a clustering of events worldwide. The observations we present here indicate that the amplitude of the low frequency waves is a control parameter of the triggering process, with a positive trigger with the Mw8.8 Maule earthquake. This suggests that only mega earthquakes can trigger SSE at the global scale, and have the potential to produce temporal clustering of large earthquakes on the scale of a few years. 
[34] Acknowledgments. This study was supported by the Agence Nationale de la Recherche (France) under the contract RA0000CO69 (G-GAP) and by project grants from CONACYT 84544 and PAPIIT IN110611, IN103808. UNM station is operated by GEOSCOPE (geoscope.ipgp.fr). We are grateful to all the participants to the G-GAP field works and to Catherine Péquegnat and Ekatarina Bourova for their work on the seismological database. We thank Paul Johnson, Yehuda Ben-Zion, Fabrice Cotton, Michel Bouchon, Cécile Lasserre, Erwan Pathier, Guillaume Bacques, Victor Cruz-Atienza, and François Renard for discussions. We also thank the Associate Editor and two anonymous reviewers for their constructive reviews.

\section{References}

Andrews, D. J. (1976), Rupture propagation with finite stress in antiplane strain, J. Geophys. Res., 81(20), 3575-3582, doi:10.1029/ JB081i020p03575.

Brown, K. M., M. D. Tryon, H. R. DeShon, L. M. Dorman, and S. Y. Schwartz (2005), Correlated transient fluid pulsing and seismic tremor in the Costa Rica subduction zone, Earth Planet. Sci. Lett., 238(1-2), 189-203, doi:10.1016/j.epsl.2005.06.055.

Campillo, M., S. Singh, N. Shapiro, J. Pacheco, and R. Herrmann (1996), Crustal structure south of the Mexican volcanic belt, based on group velocity dispersion, Geofis. Int., 35, 361-370.

Chao, K., Z. G. Peng, C. Q. Wu, C. C. Tang, and C. H. Lin (2012), Remote triggering of non-volcanic tremor around Taiwan, Geophys. J. Int. 188(1), 301-324, doi:10.1111/j.1365-246X.2011.05261.x.

Cotte, N., A. Walpersdorf, V. Kostoglodov, M. Vergnolle, J.-A. Santiago, I. Manighetti, and M. Campillo (2009), Anticipating the next large silent earthquake in Mexico, Eos Trans. AGU, 90(21), 181-182, doi:10.1029/ 2009EO210002.

Cros, E., P. Roux, J. Vandemeulebrouck, and S. Kedar (2011), Locating hydrothermal acoustic sources at Old Faithful Geyser using Matched Field Processing, Geophys. J. Int., 187(1), 385-393, doi:10.1111/ j.1365-246X.2011.05147.x.

Dascalu, C., I. R. Ionescu, and M. Campillo (2000), Fault finiteness and initiation of dynamic shear instability, Earth Planet. Sci. Lett., 177(3-4), 163-176, doi:10.1016/S0012-821X(00)00055-8.

DeMets, C., R. G. Gordon, and D. F. Argus (2010), Geologically current plate motions, Geophys. J. Int., 181(1), 1-80, doi:10.1111/j.1365-246X. 2009.04491.x.

Di Carli, S., C. Voisin, F. Cotton, and F. Semmane (2008), The 2000 western Tottori (Japan) earthquake: Triggering of the largest aftershock and constraints on the slip-weakening distance, J. Geophys. Res., 113, B05307, doi:10.1029/2007JB004951.

Dragert, H., K. L. Wang, and T. S. James (2001), A silent slip event on the deeper Cascadia subduction interface, Science, 292(5521), 1525-1528, doi:10.1126/science.1060152.

Freed, A. M. (2005), Earthquake triggering by static, dynamic, and postseismic stress transfer, Annu. Rev. Earth Planet. Sci., 33, 335-367, doi:10.1146/annurev.earth.33.092203.122505.

Ghosh, A., J. E. Vidale, Z. G. Peng, K. C. Creager, and H. Houston (2009a), Complex nonvolcanic tremor near Parkfield, California, triggered by the great 2004 Sumatra earthquake, J. Geophys. Res., 114, B00A15 doi:10.1029/2008JB006062.

Ghosh, A., J. E. Vidale, J. R. Sweet, K. C. Creager, and A. G. Wech (2009b), Tremor patches in Cascadia revealed by seismic array analysis, Geophys. Res. Lett., 36, L17316, doi:10.1029/2009GL039080.

Ghosh, A., J. E. Vidale, J. R. Sweet, K. C. Creager, A. G. Wech, and H. Houston (2010), Tremor bands sweep Cascadia, Geophys. Res. Lett., 37, L08301, doi:10.1029/2009GL042301.

Gomberg, J., and P. Johnson (2005), Seismology: Dynamic triggering of earthquakes, Nature, 437(7060), 830, doi:10.1038/437830a.

Gomberg, J., P. A. Reasenberg, P. Bodin, and R. A. Harris (2001), Earthquake triggering by seismic waves following the Landers and Hector Mine earthquakes, Nature, 411(6836), 462-466, doi:10.1038/35078053.

Gomberg, J., P. Bodin, K. Larson, and H. Dragert (2004), Earthquake nucleation by transient deformations caused by the $\mathrm{M}=7.9$ Denali, Alaska, earthquake, Nature, 427(6975), 621-624, doi:10.1038/nature02335.

Gomberg, J., J. L. Rubinstein, Z. G. Peng, K. C. Creager, J. E. Vidale, and P. Bodin (2008), Widespread triggering of nonvolcanic tremor in California, Science, 319(5860), 173, doi:10.1126/science.1149164.

Guilhem, A., Z. G. Peng, and R. M. Nadeau (2010), High-frequency identification of non-volcanic tremor triggered by regional earthquakes, Geophys. Res. Lett., 37, L16309, doi:10.1029/2010GL044660.

Hill, D. P., et al. (1993), Seismicity remotely triggered by the magnitude 7.3 Landers, California, earthquake, Science, 260(5114), 1617-1623, doi:10.1126/science.260.5114.1617.
Hirose, H., K. Hirahara, F. Kimata, N. Fujii, and S. Miyazaki (1999), A slow thrust slip event following the two 1996 Hyuganada earthquakes beneath the Bungo Channel, southwest Japan, Geophys. Res. Lett., 26(21), 3237-3240, doi:10.1029/1999GL010999.

Husker, A., S. Peyrat, N. Shapiro, and V. Kostoglodov (2010), Automatic non-volcanic tremor detection in the Mexican subduction zone, Geofis. Int., 49(1), 17-25.

Husker, A. L., V. Kostoglodov, V. M. Cruz-Atienza, D. Legrand, N. M. Shapiro, J. S. Payero, M. Campillo, and E. Huesca-Perez (2012), Temporal variations of non-volcanic tremor (NVT) locations in the Mexican subduction zone: Finding the NVT sweet spot, Geochem. Geophys. Geosyst., 13, Q03011, doi:10.1029/2011GC003916.

Ide, S. (2010), Striations, duration, migration and tidal response in deep tremor, Nature, 466(7304), 356-359, doi:10.1038/nature09251.

Itaba, S., and R. Ando (2011), A slow slip event triggered by teleseismic surface waves, Geophys. Res. Lett., 38, L21306, doi:10.1029/ 2011 GL049593.

Jaeger, J. C., and N. G. W. Cook (1979), Fundamentals of Rock Mechanics, 3rd ed., Chapman and Hall, New York.

Jay, J. A., M. E. Pritchard, M. E. West, D. Christensen, M. Haney, E. Minaya, M. Sunagua, S. R. McNutt, and M. Zabala (2012), Shallow seismicity, triggered seismicity, and ambient noise tomography at the long-dormant Uturuncu volcano, Bull. Volcanol., 74, 817-837, doi:10.1007/s00445-011-0568-7.

Kim, Y., R. W. Clayton, and J. M. Jackson (2010), Geometry and seismic properties of the subducting Cocos plate in central Mexico, J. Geophys. Res., 115, B06310, doi:10.1029/2009JB006942.

King, G. C. P., R. S. Stein, and J. Lin (1994), Static stress changes and the triggering of earthquakes, Bull. Seismol. Soc. Am., 84(3), 935-953.

Kostoglodov, V., W. Bandy, J. Dominguez, and M. Mena (1996), Gravity and seismicity over the Guerrero seismic gap, Mexico, Geophys. Res. Lett., 23(23), 3385-3388, doi:10.1029/96GL03159.

Kostoglodov, V., S. K. Singh, J. A. Santiago, S. I. Franco, K. M. Larson, A. R. Lowry, and R. Bilham (2003), A large silent earthquake in the Guerrero seismic gap, Mexico, Geophys. Res. Lett., 30(15), 1807, doi:10.1029/2003GL017219.

Kostoglodov, V., A. Husker, N. M. Shapiro, J. S. Payero, M. Campillo, N. Cotte, and R. Clayton (2010), The 2006 slow slip event and nonvolcanic tremor in the Mexican subduction zone, Geophys. Res. Lett., 37, L24301, doi:10.1029/2010GL045424.

Linde, A. T., M. T. Gladwin, M. J. S. Johnston, R. L. Gwyther, and R. G. Bilham (1996), A slow earthquake sequence on the San Andreas fault, Nature, 383(6595), 65-68, doi:10.1038/383065a0.

Manea, V. C., M. Manea, V. Kostoglodov, C. A. Currie, and G. Sewell (2004), Thermal structure, coupling and metamorphism in the Mexican subduction zone beneath Guerrero, Geophys. J. Int., 158(2), 775-784, doi:10.1111/j.1365-246X.2004.02325.x.

Marsan, D., and O. Lengline (2008), Extending earthquakes' reach through cascading, Science, 319(5866), 1076-1079, doi:10.1126/science. 1148783.

Michael, A. J. (2011), Random variability explains apparent global clustering of large earthquakes, Geophys. Res. Lett., 38, L21301, doi:10.1029/ 2011 GL049443

Miyazawa, M., and E. E. Brodsky (2008), Deep low-frequency tremor that correlates with passing surface waves, J. Geophys. Res., 113, B01307, doi:10.1029/2006JB004890.

Miyazawa, M., and J. Mori (2005), Detection of triggered deep lowfrequency events from the 2003 Tokachi-oki earthquake, Geophys. Res. Lett., 32, L10307, doi:10.1029/2005GL022539.

Miyazawa, M., and J. Mori (2006), Evidence suggesting fluid flow beneath Japan due to periodic seismic triggering from the 2004 SumatraAndaman earthquake, Geophys. Res. Lett., 33, L05303, doi:10.1029/ 2005GL025087.

Obara, K. (2002), Nonvolcanic deep tremor associated with subduction in southwest Japan, Science, 296(5573), 1679-1681, doi:10.1126/science. 1070378 .

Obara, K. (2010), Depth-dependent activity of non-volcanic tremor and other slow earthquake in the Nankai subduction zone, Abstract T43E-05 presented at 2010 Fall Meeting, AGU, San Francisco, Calif., 13-17 Dec.

Obara, K., and S. Sekine (2009), Characteristic activity and migration of episodic tremor and slow-slip events in central Japan, Earth Planets Space, 61(7), 853-862.

Obara, K., S. Tanaka, T. Maeda, and T. Matsuzawa (2010), Depthdependent activity of non-volcanic tremor in southwest Japan, Geophys. Res. Lett., 37, L13306, doi:10.1029/2010GL043679.

Ohta, Y., J. T. Freymueller, S. Hreinsdottir, and H. Suito (2006), A large slow slip event and the depth of the seismogenic zone in the south central 
Alaska subduction zone, Earth Planet. Sci. Lett., 247(1-2), 108-116, doi:10.1016/j.epsl.2006.05.013.

Okal, E. A. (2008), The generation of T waves by earthquakes, $A d v$. Geophys., 49, 1-65, doi:10.1016/s0065-2687(07)49001-x.

Outerbridge, K. C., T. H. Dixon, S. Y. Schwartz, J. I. Walter, M. Protti, V. Gonzalez, J. Biggs, M. Thorwart, and W. Rabbel (2010), A tremor and slip event on the Cocos-Caribbean subduction zone as measured by a global positioning system (GPS) and seismic network on the Nicoya Peninsula, Costa Rica, J. Geophys. Res., 115, B10408, doi:10.1029/ 2009JB006845.

Pardo, M., and G. Suarez (1995), Shape of the subducted Rivera and Cocos plates in southern Mexico: Seismic anti tectonic implications, J. Geophys. Res., 100(B7), 12,357-12,373, doi:10.1029/95JB00919.

Payero, J. S., V. Kostoglodov, N. Shapiro, T. Mikumo, A. Iglesias, X. Perez-Campos, and R. W. Clayton (2008), Nonvolcanic tremor observed in the Mexican subduction zone, Geophys. Res. Lett., 35, L07305, doi:10.1029/2007GL032877.

Peng, Z. G., and K. V. Chao (2008), Non-volcanic tremor beneath the Central Range in Taiwan triggered by the $2001 \mathrm{M}-\mathrm{w} 7.8$ Kunlun earthquake, Geophys. J. Int., 175(2), 825-829, doi:10.1111/j.1365-246X. 2008.03886.x.

Peng, Z. G., J. E. Vidale, K. C. Creager, J. L. Rubinstein, J. Gomberg, and P. Bodin (2008), Strong tremor near Parkfield, CA, excited by the 2002 Denali Fault earthquake, Geophys. Res. Lett., 35, L23305, doi:10.1029/ 2008GL036080.

Peng, Z. G., J. E. Vidale, A. G. Wech, R. M. Nadeau, and K. C. Creager (2009), Remote triggering of tremor along the San Andreas Fault in central California, J. Geophys. Res., 114, B00A06, doi:10.1029/ 2008JB006049.

Peng, Z. G., C. Q. Wu, and C. Aiken (2011), Delayed triggering of microearthquakes by multiple surface waves circling the Earth, Geophys. Res. Lett., 38, L04306, doi:10.1029/2010GL046373.

Perez-Campos, X., Y. Kim, A. Husker, P. M. Davis, R. W. Clayton, A. Iglesias, J. F. Pacheco, S. K. Singh, V. C. Manea, and M. Gurnis (2008), Horizontal subduction and truncation of the Cocos Plate beneath central Mexico, Geophys. Res. Lett., 35, L18303, doi:10.1029/2008GL035127.

Peterson, C. L., and D. H. Christensen (2009), Possible relationship between nonvolcanic tremor and the 1998-2001 slow slip event, south central Alaska, J. Geophys. Res., 114, B06302, doi:10.1029/2008JB006096.

Radiguet, M., F. Cotton, M. Vergnolle, M. Campillo, B. Valette, V. Kostoglodov, and N. Cotte (2011), Spatial and temporal evolution of a long term slow slip event: The 2006 Guerrero Slow Slip Event, Geophys. J. Int., 184(2), 816-828, doi:10.1111/j.1365-246X.2010.04866.x.

Rivet, D., M. Campillo, N. M. Shapiro, V. Cruz-Atienza, M. Radiguet, N. Cotte, and V. Kostoglodov (2011), Seismic evidence of nonlinear crustal deformation during a large slow slip event in Mexico, Geophys. Res. Lett., 38, L08308, doi:10.1029/2011GL047151.

Rogers, G., and H. Dragert (2003), Episodic tremor and slip on the Cascadia subduction zone: The chatter of silent slip, Science, 300(5627), 1942-1943, doi:10.1126/science.1084783.

Rubinstein, J. L., J. E. Vidale, J. Gomberg, P. Bodin, K. C. Creager, and S. D. Malone (2007), Non-volcanic tremor driven by large transient shear stresses, Nature, 448(7153), 579-582, doi:10.1038/nature06017.
Rubinstein, J. L., J. Gomberg, J. E. Vidale, A. G. Wech, H. Kao, K. C. Creager, and G. Rogers (2009), Seismic wave triggering of nonvolcanic tremor, episodic tremor and slip, and earthquakes on Vancouver Island, J. Geophys. Res., 114, B00A01, doi:10.1029/2008JB005875.

Ryberg, T., C. Haberland, G. S. Fuis, W. L. Ellsworth, and D. R. Shelly (2010), Locating non-volcanic tremor along the San Andreas Fault using a multiple array source imaging technique, Geophys. J. Int., 183(3), 1485-1500, doi:10.1111/j.1365-246X.2010.04805.x.

Schwartz, S. Y., and J. M. Rokosky (2007), Slow slip events and seismic tremor at circum-pacific subduction zones, Rev. Geophys., 45, RG3004, doi:10.1029/2006RG000208.

Shelly, D. R., and J. L. Hardebeck (2010), Precise tremor source locations and amplitude variations along the lower-crustal central San Andreas Fault, Geophys. Res. Lett., 37, L14301, doi:10.1029/2010GL043672.

Shelly, D. R., G. C. Beroza, and S. Ide (2007), Complex evolution of transient slip derived from precise tremor locations in western Shikoku, Japan, Geochem. Geophys. Geosyst., 8, Q10014, doi:10.1029/2007GC001640.

Shelly, D. R., Z. Peng, D. P. Hill, and C. Aiken (2011), Triggered creep as a possible mechanism for delayed dynamic triggering of tremor and earthquakes, Nat. Geosci., 4(6), 384-388, doi:10.1038/ngeo1141.

Stein, R. S., G. C. P. King, and J. Lin (1994), Stress triggering of the 1994 $\mathrm{M}=6.7$ Northridge, California, earthquake by its predecessors, Science, 265(5177), 1432-1435, doi:10.1126/science.265.5177.1432.

Stockwell, R. G., L. Mansinha, and R. P. Lowe (1996), Localization of the complex spectrum: The S transform, IEEE Trans. Signal Process., 44(4), 998-1001, doi:10.1109/78.492555.

Uenishi, K., and J. R. Rice (2003), Universal nucleation length for slipweakening rupture instability under nonuniform fault loading, J. Geophys. Res., 108(B1), 2042, doi:10.1029/2001JB001681.

Ueno, T., T. Maeda, K. Obara, Y. Asano, and T. Takeda (2010), Migration of low-frequency tremors revealed from multiple-array analyses in western Shikoku, Japan, J. Geophys. Res., 115, B00A26, doi:10.1029/ 2008JB006051.

Vergnolle, M., A. Walpersdorf, V. Kostoglodov, P. Tregoning, J. A. Santiago, N. Cotte, and S. I. Franco (2010), Slow slip events in Mexico revised from the processing of 11 year GPS observations, J. Geophys. Res., 115, B08403, doi:10.1029/2009JB006852.

Voisin, C. (2001), Dynamic triggering of earthquakes: The linear slip-dependent friction case, Geophys. Res. Lett., 28(17), 3357-3360, doi:10.1029/2001GL013101.

Voisin, C. (2002), Dynamic triggering of earthquakes: The nonlinear slipdependent friction case, J. Geophys. Res., 107(B12), 2356, doi:10.1029/ 2001JB001121.

Voisin, C., F. Cotton, and S. Di Carli (2004), A unified model for dynamic and static stress triggering of aftershocks, antishocks, remote seismicity, creep events, and multisegmented rupture, J. Geophys. Res., 109, B06304, doi:10.1029/2003JB002886.

Walpersdorf, A., N. Cotte, V. Kostoglodov, M. Vergnolle, M. Radiguet, J. A. Santiago, and M. Campillo (2011), Two successive slow slip events evidenced in 2009-2010 by a dense GPS network in Guerrero, Mexico, Geophys. Res. Lett., 38, L15307, doi:10.1029/2011GL048124.

Zigone, D., C. Voisin, E. Larose, F. Renard, and M. Campillo (2011), Slip acceleration generates seismic tremor like signals in friction experiments Geophys. Res. Lett., 38, L01315, doi:10.1029/2010GL045603. 